La ley de subcontratación y la tutela de los derechos fundamentales

de los trabajadores de servicios transitorios

Eduardo Caamaño Rojo

páginas $157-194$

\title{
LA LEY DE SUBCONTRATACIÓN Y LA TUTELA DE LOS DERECHOS FUNDAMENTALES DE LOS TRABAJADORES DE SERVICIOS TRANSITORIOS*
}

\author{
Eduardo Caamaño Rojo**
}

\begin{abstract}
RESUMEN
La dictación de la Ley $\mathrm{N}^{\circ} 20.123$ ha vuelto a posicionar el tema de la subcontratación en el Derecho del Trabajo chileno en razón de las importantes transformaciones que se introducen al sistema de regulación y protección del trabajo subordinado contenido en el Código del Trabajo, como asimismo, por las implicancias jurídicas, económicas y sociales que traerá consigo la implementación de esta normativa. El presente trabajo de investigación pretende presentar un análisis general de las modificaciones introducidas en nuestro ordenamiento laboral por este nuevo texto legal para centrarse, concretamente, en las interrogantes que genera la ley de subcontratación sobre la incidencia que tienen los derechos fundamentales de los trabajadores transitorios. Se busca así poder determinar la forma en que estas garantías esenciales del ser humano se proyectan en la especial relación jurídica de carácter triangular que se deriva de la subcontratación de servicios personales entre la empresa de servicios transitorios, la usuaria y el trabajador. De igual manera, se pretende aportar algunas ideas y soluciones sobre las posibilidades reales de amparo jurisdiccional que estos derechos fundamentales podrían obtener en caso de ser lesionados, en concordancia con las disposiciones del procedimiento de tutela que incorpora la Ley $\mathrm{N}^{\mathrm{o}} 20.087$.
\end{abstract}

* $\quad$ Recibido el 24 de abril de 2007 y aceptada su publicación con fecha 27 de mayo de 2007.

** Abogado, Doctor en Derecho, Universidad de Colonia, Alemania, Profesor de Derecho del Trabajo, Escuela de Derecho, Pontificia Universidad Católica de Valparaíso. E-mail: eduardo.caamano@ucv.cl. 


\title{
PALABRAS CLAVES
}

Subcontratación, derechos fundamentales, trabajador transitorio, contrato de trabajo, poder de dirección.

\begin{abstract}
The dictation of Law $\mathrm{N}^{\circ} 20.123$ has again positioned the sub-contracting topic in the Chilean Labor Right with regard to the important transformations that are introduced to the regulation system and the protection of the subordinated work contained in the Labor Code, as well as, for the legal, economic and social consequences that will involve the implementation of this rule. The current research work intends to show a general analysis of the modifications introduced in our labor ordinance by this new legal text, to focus, specifically, in the questions produced by the sub-contracting law about the incidence that fundamental rights of temporary workers have. That way it is searched to be able to determine the way in which these essential guarantees of the human being are projected in the special legal relation of a triangle character derived from the personal service sub-contracting between the temporary service company, the user and the worker. Similarly, it is intended to provide some ideas and solutions about the real possibilities of the jurisdictional protection these fundamental rights might get in case of being injured, in agreement with the provisions of the guardianship procedure incorporated by Law $\mathrm{N}^{\mathrm{o}} 20.087$.
\end{abstract}

\section{PALABRAS CLAVES}

Sub-contracting, fundamental rights, temporary worker, employment contract, direction power.

\section{Algunas consideraciones previas}

La dictación de la Ley $\mathrm{N}^{\mathrm{o}} 20.123$ que regula el trabajo en régimen de subcontratación, el funcionamiento de las empresas de servicios transitorios y el contrato de trabajo de servicios transitorios, ${ }^{1}$ cuya entrada en vigencia tuvo lugar el día 14 de enero de $2007,{ }^{2}$ ha vuelto a posicionar el tema de la subcontratación laboral en el Derecho del Trabajo chileno en razón de

Publicada en el Diario Oficial de fecha 16 de octubre de 2006.

Así lo ha confirmado expresamente la Dirección del Trabajo a través del dictamen 5476/099, de fecha 28 de diciembre de 2006. Además, el mismo dictamen ha precisado que las disposiciones introducidas al CdT por la Ley $\mathrm{N}^{\mathrm{o}} 20.123$ comenzarán también a regir desde el 14 de enero de 2007 respecto de las empresas que al 16 de octubre de 2006 estaban realizando actividades de puesta a disposición de trabajadores, sin perjuicio que tales empresas cuentan con un plazo de 180 días contados desde el 14 de enero de 2007 para solicitar su inscripción en el registro al que se refiere el artículo $183-\mathrm{K}$ del CdT. 
La ley de subcontratación y la tutela de los derechos fundamentales de los trabajadores de servicios transitorios

las importantes transformaciones que se introducen al sistema de regulación y protección del trabajo subordinado contenido en el Código del Trabajo (CdT), como asimismo, por las implicancias jurídicas, económicas y sociales que traerá consigo la implementación de esta nueva normativa. ${ }^{3}$ Sobre el particular es importante destacar que la Ley $\mathrm{N}^{\mathrm{o}} 20.123$ vino a poner fin a un vacío de nuestra legislación laboral, que se arrastraba desde hace bastante tiempo, y que generaba arduas discusiones en cuanto a la conveniencia de regular el tema de la subcontratación. ${ }^{4}$ Es así como la complejidad y la falta de uniformidad de criterios sobre la subcontratación quedó de manifiesto luego que esta materia se excluyera expresamente del proyecto original de reforma laboral enviado al Congreso Nacional el año 1999, convertido más tarde en la Ley $\mathrm{N}^{\circ} 19.759$, en gran medida, debido a la falta de consenso político y jurídico que motivaba la regulación propuesta. Por esta razón se envió un proyecto de ley específico sobre la subcontratación en mayo de 2002 y se buscó de esa manera someter el tema a una discusión parlamentaria más extensa, lo que implicó la prolongación de la tramitación del proyecto por varios años hasta que circunstancias político electorales vividas a comienzos del año 2006 volvieron a poner el tema en palestra, motivando el interés por despachar definitivamente la ley que nos ocupa en este estudio.

A vía introductoria es necesario destacar que hasta antes de la entrada en vigencia de la Ley $\mathrm{N}^{\mathrm{o}} 20.123$, la subcontratación se mantuvo regulada de forma indirecta en los artículos 64 y 64 bis del CdT a propósito de la protección de las remuneraciones, ${ }^{5}$ mientras que su variante más compleja, referida al suministro de trabajadores, quedó entregada a una suerte de indeterminación jurídica con los consecuentes riesgos de desprotección que ello significó para una gran cantidad de personas empleadas en esas condiciones ${ }^{6}$ y que se resolvía, en los casos concretos, mediante la aplicación del principio de primacía de la realidad ${ }^{7}$, la presunción de

Véase: Echeverría Tortello, Magdalena, "Los riesgos laborales de la subcontratación”, Aporte al Debate Laboral No 9, Departamento de Estudios de la Dirección del Trabajo, abril 2006, disponible en www.dt.gob.cl.

4 Sobre la materia: Ugarte Cataldo, José Luis, El nuevo Derecho del Trabajo, Editorial Universitaria, Santiago, Chile, 2004, p. 97 s. Véase también la historia de la Ley No 20.123 disponible en www.bcn.cl.

5 Ver: Lanata Fuenzalida, Gabriela, Contrato individual de trabajo, Editorial Lexis Nexis, Santiago, Chile, 2006, p. 175 s. Sobre los precedentes normativos de la regulación de la subcontratación en Chile véase: Walker Errázuriz, Francisco, Derecho de las Relaciones Laborales, Editorial Universitaria, Santiago, Chile, 2003, p. 424-425; Palavecino, Claudio, Subcontratación. Régimen jurídico del trabajo subcontratado y del suministro de personal, Editorial Jurídica de Chile, Santiago, Chile, 2006, p. 23 s.

$6 \quad$ Sobre el particular es importante considerar que la Encuesta Laboral de la Dirección del Trabajo, ENCLA 2004, estableció que la proporción de trabajadores suministrados llega a un 7.3\% del total de trabajadores con que cuentan las empresas, lo que a nivel del país implicaría que en el año en que se realizó la muestra más de 220.000 personas prestaban servicios bajo esta modalidad, sin perjuicio que la tendencia establecida por esta encuesta da cuenta un crecimiento sostenido de esta forma de empleo para el futuro. Por otra parte, es interesante destacar que de acuerdo a la ENCLA las ramas de actividad en que más se utiliza el suministro de trabajadores son: la industria, el comercio y la agricultura. El texto completo de la encuesta está disponible en: www.dt.gob.cl Este principio significa que en caso de discordancia entre lo que ocurre en la práctica y lo que surge de los documentos o acuerdos, debe darse preferencia a lo primero, es decir, a lo que sucede en el terreno de los 
representación del empleador del artículo 4 inciso 1 del CdT y la presunción de laboralidad del artículo 8 inciso 1 del $\mathrm{CdT}^{8}{ }^{2}$ lo que implicaba, en último término, reconocerle la calidad de empleador a aquél que recibiera los servicios y ejerciera el poder de dirección. ${ }^{9}$ Estas soluciones que no permitían resolver de manera general el problema de la inseguridad jurídica y de la precariedad laboral en la que se encontraban inmersos muchos trabajadores eran a todas luces insuficientes, pues desconocían las verdaderas particularidades de esta modalidad de contratación laboral y, a lo más, alcanzaban la obtención de un cierto grado de tutela en el plano de los derechos individuales, pero sin resolver de manera óptima las dificultades que se presentaban en el desarrollo concreto de la actividad laboral, por ejemplo, en materia de higiene y seguridad en el trabajo, ni respecto de materias de trascendental importancia como lo son los derechos de sindicación y de negociación colectiva. ${ }^{10}$

Además, la solución derivada del acuerdo transaccional obtenido en el Congreso Nacional el año 2001 en orden a postergar la regulación de la subcontratación y que se reflejó en parte en el nuevo texto del artículo 478 del CdT incorporado por la Ley $N^{\circ} 19.759$ no fue satisfactoria. En efecto, dicha norma, que fue concebida con el fin de otorgar un cierto resguardo a los trabajadores suministrados, sancionando la simulación de la contratación de trabajadores a través de terceros, así como los subterfugios destinados a ocultar, disfrazar o alterar la individualización o patrimonio de la empresa con vistas a afectar los derechos individuales y/ o colectivos de los trabajadores, no contribuyó a mejorar la situación laboral y previsional de los trabajadores subcontratados, debido a la dificultad que implicaba el establecimiento de este

hechos. Como consecuencia de lo anterior, "la mayoría de las normas que constituyen el Derecho del Trabajo se refieren más que al contrato, considerado como negocio jurídico y a su estipulación, a la ejecución que se da al mismo por medio de la prestación del trabajo." (Corte Suprema, sentencia de fecha 16 de marzo de 1987, rol Nr. 21.950). En igual sentido, sentencia de la Corte Suprema de fecha 31 de marzo de 2003, Rol № 2.739-02.

8 "En otras palabras, la ley supone la existencia de un contrato de esta índole siempre que exista una situación coexistente en que dos se han obligado recíprocamente, una a prestar servicios personales bajo dependencia y subordinación de otra, que se obliga a pagar por estos servicios una remuneración determinada, correspondiendo el carácter de empleador a la persona natural o jurídica que utiliza los servicios intelectuales o materiales y la calidad de trabajador, a la persona natural que presta esos servicios, bajo dependencia o subordinación." Así lo afirma la Corte Suprema en sentencia de fecha 24 de enero de 2002, rol No 4531-01.

9 Así lo reconoció la Dirección del Trabajo a través de sus pronunciamientos sobre las empresas de colocación y los contratos de enganche, particularmente, los dictámenes $\mathrm{N}^{\circ} 9067 / 274$ de fecha 9 de diciembre de 1987 y $\mathrm{N}^{\circ}$ 5487 de 22 de septiembre de 1992.

10 Desafortunadamente, según veremos, la Ley Nº 20.123 tampoco resolvió la problemática del ejercicio de los derechos colectivos de los trabajadores que son suministrados para prestar servicios en otra empresa distinta a la de su empleador, lo que da cuenta de un problema de fondo de nuestro actual sistema jurídico laboral para reconocer y fomentar ampliamente el ejercicio de los derechos de sindicación y de negociación colectiva, en aras a remediar la baja incidencia que el desarrollo de la actividad sindical y de la negociación colectiva tiene en el país, lo que es fuente de distorsiones en el mercado de trabajo y reflejo de un grave problema social que urge remediar. En igual sentido: Ugarte Cataldo, José Luis, "Sobre las relaciones triangulares: la subcontratación y el suministro de trabajadores", Revista Ius et Praxis, Facultad de Ciencias Jurídicas y Sociales, Universidad de Talca, Año 12, No 1, 2006, p. 28-29. 
La ley de subcontratación y la tutela de los derechos fundamentales de los trabajadores de servicios transitorios

ilícito laboral y por la discusión generada acerca de si era o no necesario establecer una conducta dolosa del empleador para poder configurarlo y hacer efectivas las sanciones pecuniarias. ${ }^{11}$

En definitiva, esta breve exposición de la situación existente con anterioridad a la entrada en vigencia de la Ley $\mathrm{N}^{\circ} 20.123$ permite evidenciar que la regulación de la subcontratación laboral en cualquiera de sus variantes representaba una verdadera necesidad, pues su dictación vino a remediar en parte importante la precariedad que afectaba a los trabajadores subcontratados y contribuirá, idealmente, a identificar en forma clara a las empresas que subcontratan, deslindando sus responsabilidades y posibilidades de actuación en armonía con el debido respeto de los derechos de los trabajadores. Por otro lado, es de esperar que la Ley $\mathrm{N}^{\mathrm{o}} 20.123$ permita también transparentar y ordenar el mercado en el cual operan estas empresas, el que, en base a las nuevas y mayores exigencias incorporadas al CdT, debiera tender a dar preferencia a las entidades más solventes y responsables desde el punto de vista del correcto cumplimiento de la legislación laboral, lo que podría ser sin duda el principal aporte de esta nueva normativa.

De igual manera, es posible imaginar que las recién incorporadas disposiciones sobre la subcontratación de servicios personales podrían contribuir a potenciar la obtención de empleo para nuevos trabajadores a través de la intermediación de las empresas de servicios transitorios, al hacer más práctico o rentable para las empresas que buscan personal el tener por un tiempo bajo su dirección a un trabajador transitorio, sin tener que iniciar un proceso, a veces costoso, de búsqueda y selección. ${ }^{12}$ Con todo, la evaluación de la verdadera incidencia práctica de la

11 Véase: Ugarte Cataldo, José Luis, El nuevo Derecho del Trabajo, ob. cit., p. 104 s. Por su parte, la Dirección del Trabajo a través del dictamen $\mathrm{N}^{\circ}$ 0922/0025, de fecha 11 de marzo de 2003 resolvió que: “...en rigor, la figura que el inciso primero del artículo 478 trata, como una situación de fraude por la vía de simulación del empleador, que se configura por la presencia de un resultado elusivo de la legislación laboral, y más específicamente de las normas imperativas referidas a quien es el empleador y a quien debe responder por las obligaciones laborales, supuesto fundamental de la aplicación de todo el resto de la normativa legal laboral, y razón de la gravedad y disvalor que el legislador ha asociado a este ilícito laboral, especialmente cuando el tercero no hace sino jugar única y exclusivamente un rol de aparente empleador, y que se expresa, por una parte, en una de las más altas multas administrativas contempladas en nuestra legislación laboral, sujeta a la revisión judicial respectiva, y por otra, en el establecimiento de un sistema de responsabilidad solidaria entre los involucrados. Precisamente, la gravedad de la conducta fraudulenta a la que se refiere el inciso primero del artículo 478 del Código del Trabajo, ha llevado al legislador ha prescindir de la expresión "dolosamente", lo que viene a relevar que se trata de una conducta objetivamente disvaliosa y que merece el reproche jurídico por encubrir a las partes del verdadero vínculo laboral, más allá de la presencia o no de una determinada intencionalidad de perjudicar a otro sujeto o de obtener un resultado prohibido. La historia de la ley no deja margen a dudas, quedando claramente establecido que el fraude a la ley laboral contemplado por dicho precepto, sólo exige la existencia del resultado de elusión de las normas legales sobre la identidad del empleador, mediante la interposición de un tercero, situación considerada especialmente disvaliosa por el legislador por las razones indicadas, prescindiendo de la exigencia de una determinada intencionalidad o dolo."

12 Así lo ha entendido también el legislador español, al señalar en la exposición de motivos de la Ley № 14/1994 que reguló las empresas de trabajo temporal que cuando la actividad de estas empresas: “... se desarrolla de 
regulación sistemática de la subcontratación que introduce la ley en comento debiera ser objeto de un examen detallado en un mediano plazo, con el objeto de remediar las falencias o desviaciones que su aplicación pudiera traer aparejadas y así fortalecer su fin último de mejorar la situación laboral de los trabajadores subcontratados.

Sin perjuicio de lo anterior, no se puede desconocer que la Ley $\mathrm{N}^{\circ} 20.123$ dista de ser un texto legal perfecto desde el punto de vista jurídico, lo que en gran medida es el resultado de una técnica legislativa transaccional producto del equilibrio de poder alcanzado en un momento dado entre las fuerzas políticas representadas en el Congreso Nacional, ${ }^{13}$ lo que se traduce en una serie de deficiencias y de insuficiencias que deberán ser aclaradas, tanto por la jurisprudencia administrativa $^{14}$ y judicial, como por la doctrina y, eventualmente, por medio de futuras leyes modificatorias. Es por eso que, en lo que atañe a este estudio, el análisis se centrará en las interrogantes que genera la nueva ley de subcontratación sobre la incidencia efectiva que tendrían los derechos fundamentales de los trabajadores suministrados para contribuir a mejorar su condición laboral en base al respeto a la libertad y dignidad de la persona que estas garantías conllevan, toda vez que se hace un mero reconocimiento genérico a ellos en el artículo 183-Y del CdT. Asimismo, se pretende aportar algunas ideas y soluciones sobre las posibilidades reales de tutela jurisdiccional que estos derechos fundamentales podrían obtener en caso de ser lesionados, en concordancia con las disposiciones del procedimiento de tutela que incorpora la Ley $N^{\circ} 20.087$ y que, luego de la lamentable decisión del Gobierno adoptada recientemente de postergar su entrada en vigencia, sólo comenzará a operar en marzo de $2008 .^{15}$

forma debidamente controlada, lejos de perjudicar a los trabajadores por ellas contratados pueden canalizar un volumen muy importante de empleo cuya especialización e inmediatez en la respuesta, sobre todo en el sector servicios, no puede ofrecerse a través de los mecanismos tradicionales. Por otra parte, para los trabajadores constituye un mecanismo importante para acceder a la actividad laboral y para familiarizarse con la vida de la empresa, posibilitando además una cierta diversificación profesional y formación polivalente, a la vez que, en determinados casos, facilita a ciertos colectivos un sistema de trabajo que les permite compaginar la actividad laboral con otras ocupaciones no productivas o responsabilidades familiares."

13 Lamentablemente, esta forma de legislar pareciera ser la tónica dominante si se analizan las principales leyes laborales dictadas en el último tiempo, como es el caso, por ejemplo de la Ley $\mathrm{N}^{\circ} 20.087$ que sustituye el actual procedimiento laboral, en la que la normativa propuesta en el proyecto enviado por el Ejecutivo, luego de años de un acabado estudio técnico jurídico, terminó gravemente trastocada y desvirtuada en algunas materias, producto de los consensos políticos de último minuto. El caso más emblemático de ello es la limitación artificial que se introduce al procedimiento de tutela, restringiendo su aplicación sólo a algunos derechos fundamentales, por lo que el futuro tendremos garantías de primera y segunda categoría, según ofrezcan o no posibilidades de resguardo (ver artículo 485 del CdT incorporado por la ley referida), siendo lo más inexplicable racionalmente la restricción de la tutela del derecho a la no discriminación, lo que podría significar en la práctica la perpetuación de la vergonzosa situación de discriminación que afecta a miles de trabajadores en Chile, particularmente, mujeres y jóvenes.

14 Véase el dictamen de la Dirección del Trabajo $\mathrm{N}^{\circ}$ 141/05, de fecha 10 de enero de 2007, que fija el sentido y alcance de los artículos 183-A a 183-D del CdT.

15 Postergación aprobada por la Ley No 20.164, publicada en el Diario Oficial de fecha 14 de febrero de 2007. 
La ley de subcontratación y la tutela de los derechos fundamentales de los trabajadores de servicios transitorios

\section{Causas de la subcontratación laboral}

Sin pretender entrar al detalle sobre este punto, por exceder los límites del estudio propuesto, queremos efectuar una referencia general a las causas que explican la incidencia creciente de la subcontratación en el mercado laboral en vistas a poder proporcionar elementos de juicio que contribuyan a clarificar el sentido de la normativa incluida por la Ley $\mathrm{N}^{\circ} 20.123$, así como la transformación que ésta conlleva al modelo general de ordenación y protección del trabajo subordinado. Por esta razón, cabe señalar que al momento de buscar explicaciones para entender el enorme desarrollo e influjo que ha tenido la subcontratación laboral en los últimos años, existe consenso para sostener que uno de los principales agentes modificadores de las tradicionales estructuras de organización empresarial, junto con el desarrollo de las nuevas tecnologías o la globalización, ha sido el fenómeno de la descentralización productiva, ${ }^{16}$ que se conoce también por su denominación en inglés "outsourcing". ${ }^{17}$ Ahora bien, la descentralización productiva se puede conceptualizar, siguiendo al profesor Cruz Villalón, ${ }^{18}$ como: "la forma de organización del proceso de elaboración de bienes o de prestación de servicios para el mercado final de consumo, en virtud del cual una empresa decide no realizar directamente a través de sus medios materiales y personales ciertas fases o actividades precisas para alcanzar el bien final de consumo, optando en su lugar por desplazarlas a otras empresas o personas individuales, con quienes establece acuerdos de cooperación de muy diverso tipo."

Ante este cambio en la forma en que las empresas desarrollan su actividad se puede destacar que la descentralización productiva ha remecido las formas clásicas de prestación de servicios personales al interior de la empresa, ${ }^{19}$ lo que se explica, en opinión de Rivero Lamas, ${ }^{20}$ porque a partir de la década de 1980, un conjunto de factores impulsaron una profunda reestructuración económica que trascendería, entre otros ámbitos, a las estrategias de organización de las empresas. El objeto subyacente a estos nuevos cambios fue hacer frente a la incertidumbre causada por unas rápidas mutaciones en el entorno económico, institucional y tecnológico de las empresas, para lo que era preciso introducir más flexibilidad en la producción, gestión y

16 En detalle: Caamaño Rojo, Eduardo, "Las transformaciones del trabajo, la crisis de la relación laboral normal y el desarrollo del empleo atípico", Revista de Derecho de la Facultad de Ciencias Jurídicas y Sociales, Universidad Austral de Chile - Valdivia, volumen XVIII, julio 2005, p. 25 s.

17 El término outsourcing es una contracción de las palabras inglesas outside resource using y se puede traducir como uso de recursos externos o externalización productiva.

18 Cruz Villalón, Jesús, "Outsourcing y relaciones laborales”, en VV.AA., Descentralización productiva y nuevas formas organizativas del Trabajo, Colección Informes y Estudios, Ministerio del Trabajo y Asuntos Sociales, Madrid, España, 2000, p. 253.

19 En igual sentido: Del Rey Guanter, Salvador; Gala Durán, Carolina, "Trabajo autónomo y descentralización productiva: nuevas perspectivas de una relación en progresivo desarrollo y dependencia", documento disponible en www.ceveal.com/autonomos.htm.

20 Rivero Lamas, Juan, "La descentralización productiva y las nuevas formas organizativas del trabajo", en VV.AA., Descentralización productiva y nuevas formas organizativas del Trabajo, Colección Informes y Estudios, Ministerio del Trabajo y Asuntos Sociales, Madrid, España, 2000, p. 21-22. 
comercialización. ${ }^{21}$ A la postre, era preciso arbitrar nuevas estrategias de organización y de gestión, porque ni las grandes ni las pequeñas empresas se consideraban ya por si solas capaces de desenvolverse y progresar en una muy diferente situación económica que condicionaba su sistema de producción y la posibilidad de cumplir en los mercados. Desde esta óptica, se debe reconocer que una de las principales razones que también ha llevado a los procesos de descentralización productiva ha sido también la necesidad de controlar y reducir los costos laborales, haciéndolos variables, y lograr con ello un mayor margen de libertad incontrolada de decisión empresarial respecto al factor trabajo. Es así, como la diversidad de manifestaciones de externalización productiva desarticula la organización social de la empresa tradicional, diversifica lo que, como grupo de referencia, era compacto y definido, y transforma profundamente las relaciones laborales, al mismo tiempo que debilita el poder sindical no bien adaptado todavía a esta nueva configuración del trabajo y del sistema de empresas. ${ }^{22}$

Esta nueva e incierta realidad producirá una serie de cambios en la organización empresarial que repercutirán directamente en el desarrollo de los trabajos prestados bajo subordinación y por cuenta ajena, ${ }^{23}$ como asimismo, incidirán abiertamente en los modelos de regulación asumidos por la legislación laboral tradicional, la que en muchos casos carecerá de una respuesta normativa eficaz frente a las nuevas modalidades de contratación surgidas de este proceso de transformación. Por lo tanto, el ordenamiento jurídico laboral deberá adaptarse a este nuevo escenario, alterando los principios e instituciones clásicas del Derecho del Trabajo, como lo son, por ejemplo, el principio de primacía de la realidad y la noción de empleador, con mirar a materializar también para estas nuevas realidades laborales el fin protector que define y particulariza a esta rama del Derecho. ${ }^{24}$

$21 \quad$ Sobre el particular se sostiene que: "en concreto, la actitud dominante en la gestión empresarial frente al desafío de la flexibilidad propio de la globalización, y en búsqueda de la ansiada competitividad, se podrá resumir en tres palabras estratégicas: reorganizar (re-engeneering), reducir (downsizing) y desplazar (outsourcing). Así, dentro de este ideario de la empresa flexible jugará un rol estratégico y fundamental la descentralización productiva, siendo un instrumento de flexibilización de las estructuras productivas que ha permitido a éstas adaptarse a un mercado turbulento y diversificado. En efecto, la organización de la empresa, y de todo proceso laboral, será sistemáticamente fragmentado en elementos separados y autónomos, progresivamente expulsados de la empresa y entregados a terceros." En este sentido: Ugarte Cataldo, José Luis, El nuevo Derecho del Trabajo, ob. cit., p. 89-90. Véase también: Caamaño Rojo, Eduardo, "Las transformaciones del trabajo, la crisis de la relación laboral normal y el desarrollo del empleo atípico", ob. cit., p. $25 \mathrm{~s}$.

22 Rodríguez-Piñero, Miguel, "Prólogo" del libro VV.AA., Descentralización productiva y nuevas formas organizativas del Trabajo, Colección Informes y Estudios, Ministerio del Trabajo y Asuntos Sociales, Madrid, España, 2000, p. 15.

23 En detalle: Ugarte Cataldo, José Luis, "La descentralización productiva: la nueva moda en las relaciones laborales", Revista Laboral Chilena, enero 2001, p. 58 s.

24 En detalle: Caamaño Rojo, Eduardo, "Las transformaciones del trabajo, la crisis de la relación laboral normal y el desarrollo del empleo atípico", ob. cit., p. 25 s. Véase también: Rojas Miño, Irene, "Los desafíos actuales del Derecho del Trabajo en Chile", Revista Ius et Praxis, Facultad de Ciencias Jurídicas y Sociales, Universidad de Talca, Año 12, No 1, 2006, p. 235 s. 
La ley de subcontratación y la tutela de los derechos fundamentales de los trabajadores de servicios transitorios

Es precisamente en este contexto en el que adquiere una nueva dimensión la problemática de la subcontratación laboral y, en particular, una de las variantes que analizaremos en el acápite siguiente y que supone la intermediación de servicios personales por parte de una empresa a otra, pues ella se desarrolla a partir de estos procesos de transformación y viene a erigirse como una respuesta empresarial ante la nueva realidad económica, demandando, desde la perspectiva de los trabajadores, un sistema jurídico de protección que se adapte a una configuración de las relaciones contractuales entre empresas y trabajadores que era inimaginable al momento de concebir el ordenamiento laboral que surgió como una respuesta directa a la cuestión social.

\section{Formas de subcontratación laboral}

En lo que dice relación con las formas en que se manifiesta la tercerización se suelen identificar dos clases de subcontratación laboral en base a lo que constituye el objeto de ésta, vale decir bienes y servicios o trabajo. ${ }^{25}$

\subsection{La subcontratación de bienes y servicios}

La subcontratación de bienes y servicios se particulariza, como lo plantea Echeverría, ${ }^{26}$ porque en ella se relacionan dos entidades independientes entre sí, una de las cuales realiza el encargo por su cuenta y riesgo, con sus materiales e instrumentos y su propio personal. Así esta forma de subcontratación se refiere al ámbito de las relaciones que se establecen entre dos empresas en las que una de ellas encarga a la otra la producción de bienes o la prestación de servicios, que la otra empresa se compromete a realizar por sí misma y con sus propios recursos financieros, materiales y humanos. ${ }^{27}$

Véase por ejemplo: Echeverría, Magdalena; Solís, Valeria; Uribe, Verónica, "El otro trabajo: el suministro de trabajadores en las empresas", Cuaderno de Investigación No 7, Dirección del Trabajo, Santiago, Chile, 1998; Torres Díaz, Roberto, "La reforma laboral, los contratistas y las empresas de servicios transitorios", Revista Laboral Chilena, julio 2001 (Parte I), p. 72 s.; agosto 2001 (Parte II), p. 80 s.; Koch, Carlos, "Contratos de provisión de trabajadores. La relación laboral de trabajo triangular", Revista Laboral Chilena, febrero marzo 1997, p. 87 s.; Ugarte Cataldo, José Luis, "Suministro de trabajadores y trabajo temporal. ¿Empresas sin trabajadores?", Revista Laboral Chilena, junio 1998, p. 76 s.; Monereo, José Luis, La responsabilidad empresarial en los procesos de subcontratación: puntos críticos, ediciones Ibidem, Madrid, España, 1994; Dieterich, Thomas; Hanau, Meter; Schaub, Günter, Erfurter Komentar zum Arbeitsrecht, $3^{\mathrm{a}}$ edición, Editorial C.H. Beck, München, Alemania, 2003, p. 542 s.; Monereo Pérez, José Luis; Moreno Vida, María Nieves, "Las empresas de trabajo temporal en el marco de las nuevas formas de organización empresarial", Revista del Ministerio del Trabajo y Asuntos Sociales No 48, España, 2004, p. 39 s.; García Murcia, Joaquín, "Contratas y subcontratas", Revista del Ministerio del Trabajo y Asuntos Sociales No 48, España, 2004, p. 13 s.; Ugarte Cataldo, José Luis, "Sobre las relaciones triangulares: la subcontratación y el suministro de trabajadores", ob. cit., p. 14.

26 Echeverría Tortello, Magdalena, "Los riesgos laborales de la subcontratación”, ob. cit., p. 11.

27 En igual sentido: Lizama Portal, Luis, Derecho del Trabajo, Editorial Lexis Nexis, Santiago, Chile, 2003, p. 51 s. Este autor ha definido la subcontratación laboral, en su variante de bienes y servicios, como: “... una modalidad de contratación en la que una empresa, dueña de una obra o faena, contrata a otra empresa 
Como ya se señalara, esta es la forma de subcontratación a la que se referían implícitamente los derogados artículos 64 y 64 bis del CdT al establecer una forma especial de protección a las remuneraciones de los trabajadores de las empresas contratistas y subcontratistas. En la actualidad, la Ley $\mathrm{N}^{\mathrm{O}} 20.123$ explicitó y sistematizó la regulación de esta forma de subcontratación en el Párrafo $1^{\circ}$ del Título VII del Libro I que se incorpora al CdT. En particular, la nueva normativa se refiere a esta clase de tercerización en el artículo 183-A del CdT, el cual en su inciso 1 define al trabajo en régimen subcontratación como: "... aquel realizado en virtud de un contrato de trabajo por un trabajador para un empleador, denominado contratista o subcontratista, cuando éste, en razón de un acuerdo contractual, se encarga de ejecutar obras o servicios, por su cuenta y riesgo y con trabajadores bajo su dependencia, para una tercera persona natural o jurídica dueña de la obra, empresa o faena, denominada empresa principal, en la que se desarrollan los servicios o se ejecutan las obras contratadas." De la definición anterior se puede colegir que el trabajo en régimen de subcontratación tiene como supuesto un complejo de relaciones jurídicas constituido por un contrato de carácter civil o comercial que vincula a una empresa que requiere la ejecución de una obra o un servicio con otra que se obliga a efectuarlo y, a su vez, por uno o varios contratos de trabajo que vinculan a esta última con el o los trabajadores que colaboran en su ejecución. ${ }^{28}$

Por su parte, en lo que respecta al desarrollo y ordenación de las relaciones laborales, cabe precisar que no se presenta en esta clase de subcontratación una alteración del arquetipo del contrato individual de trabajo regulado a partir del artículo 7 y siguientes del CdT, ya que la relación jurídica se concreta entre el empleador, empresa contratista, ${ }^{29}$ y cada trabajador, o entre el empleador, empresa subcontratista, con cada uno de sus trabajadores, no teniendo la empresa mandante o dueña de la obra o faena parte alguna en ellas, pues ésta sólo se vincula contractualmente en base a la normativa civil o comercial con la empresa contratista, lo que ocurre de la misma forma entre la empresa contratista y la subcontratista. ${ }^{30}$ Por lo tanto, la

(denominada contratista) mediante un contrato civil o comercial, para que ejecute a su cuenta y riesgo y, con sus propios trabajadores, un determinado trabajo o servicio, pudiendo esta última, a su vez, contratar a otra empresa (denominada subcontratista) para que lleve a cabo el trabajo o servicio requerido."

28 Palavecino, Claudio, Subcontratación. Régimen jurídico del trabajo subcontratado y del suministro de personal, ob. cit., p. 30. Véase también: Walker Errázuriz, Francisco, Derecho de las relaciones laborales, ob. cit., p. 421-422; Lizama Portal, Luis, Derecho del Trabajo, ob. cit., p. 51-52.

29 La Dirección del Trabajo mediante el dictamen Nr. 9159/242, de fecha 14 de diciembre de 1990, definió al contratista como: "aquella persona natural o jurídica que, mediante un contrato, ejecuta para un tercero dueño de una obra, empresa o faena, labores de ejecución o prestaciones de servicio mediante un precio convenido, contratando para ello los trabajadores."

30 Así lo ha confirmado recientemente la Dirección del Trabajo a través del dictamen $\mathrm{N}^{\mathrm{o}}$ 141/05, de fecha 10 de enero de 2007, al precisar que la subcontratación: “...exige que las obras o servicios que ejecuta el contratista para la empresa principal, deben ser realizadas con trabajadores de su dependencia. En otros términos, la prestación de servicios de los trabajadores del contratista debe ejecutarse bajo un vínculo de subordinación y dependencia respecto de éste, el cual, conforme a la doctrina y jurisprudencia administrativa vigente, se traduce, entre otros aspectos, en el derecho del empleador a dirigir al trabajador impartiéndole órdenes e instrucciones, 
La ley de subcontratación y la tutela de los derechos fundamentales de los trabajadores de servicios transitorios

forma tradicional de entender las relaciones jurídicas entre el trabajador y el empleador no se ve alterada de manera alguna, pues está claro el contenido de la prestación que debe el trabajador al empleador, como a su vez, las obligaciones que asume el empleador como contraparte de la relación laboral y titular de los poderes de dirección y de control. ${ }^{31}$ Es por esto, entonces, como lo plantea Ugarte, ${ }^{32}$ que en esta forma de subcontratación lo que interesa es velar por el cumplimiento efectivo de la legislación existente, especialmente de la responsabilidad subsidiaria de la empresa principal o mandante, y en la equiparación de las condiciones salariales entre estos trabajadores y los que están directamente contratados por la empresa dueña de la obra.

Ahora bien, las innovaciones introducidas por la Ley $\mathrm{N}^{\circ} 20.123$ en esta materia apuntan fundamentalmente a precisar la responsabilidad subsidiaria, y en algunos casos solidaria, de la empresa principal frente a las obligaciones laborales y previsionales de dar ${ }^{33}$ que afecten a las empresas contratistas y subcontratistas, perfeccionando como contrapartida los derechos de información ${ }^{34}$ y retención de la empresa principal, consagrados en el actual artículo 183-C del CdT. ${ }^{35}$ Si cabe destacar de manera somera una verdadera innovación normativa respecto de la subcontratación de bienes y servicios, entonces se debe mencionar el fortalecimiento de la protección de los trabajadores de las empresas contratistas y subcontratistas en materia de seguridad laboral, en orden a establecer una responsabilidad directa de la empresa principal en

principalmente acerca de la forma y oportunidad de la ejecución de las labores, y en el deber del trabajador de acatar y obedecer las mismas. De esta suerte, en el régimen de subcontratación que nos ocupa, es el contratista, en su carácter de empleador, el que estará dotado de la facultad de supervigilar a los trabajadores que se desempeñen en las obras o servicios que realiza para la empresa principal, como asimismo, para impartirles las instrucciones que estime pertinentes y ejercer los controles necesarios para tales efectos, sin que corresponda a la empresa principal ingerencia alguna al respecto."

31 En igual sentido: Walker Errázuriz, Francisco, Derecho de las relaciones laborales, ob. cit., p. 420.

32 Ugarte Cataldo, José Luis, "Sobre las relaciones laborales triangulares: la subcontratación y el suministro de trabajadores," ob. cit., p. 15.

33 En relación con estas obligaciones el dictamen $\mathrm{N}^{\circ}$ 141/05 de la Dirección del Trabajo ha establecido que las obligaciones laborales de dar alcanza a: “...todas aquellas obligaciones que, derivando de los contratos individuales o colectivos de trabajo o del Código del Trabajo y sus leyes complementarias, consistan en el pago de una suma de dinero determinada.” Por su parte, tratándose de las obligaciones previsionales de dar se señala que: "...la responsabilidad solidaria de la empresa principal y el contratista sólo alcanzará al pago de las cotizaciones de seguridad social de los trabajadores de que se trata."

34 Véase el Decreto Supremo No 319 del Ministerio del Trabajo y Previsión Social, de fecha 13 de diciembre de 2006, que aprueba el Reglamento del artículo 183-C inciso segundo del Código del Trabajo, incorporado por la Ley $\mathrm{N}^{\circ} 20.123$, sobre acreditación de cumplimiento de obligaciones laborales y previsionales (texto disponible en www.mintrab.cl). La importancia de este reglamento radica en que el derecho de información de la empresa principal o contratista se ejercerá mediante la acreditación del monto y estado de cumplimiento de las obligaciones laborales y previsionales de los contratistas y subcontratistas, según sea el caso. Esta acreditación deberá verificarse a través de certificados emitidos por la respectiva Inspección del Trabajo, o bien por medios idóneos que garanticen la veracidad de dicho monto y estado de cumplimiento, todo lo cual es precisado y regulado en este Decreto Supremo.

35 Véase un análisis crítico sobre los fundamentos de la responsabilidad que se asigna a la empresa principal en: Palavecino, Claudio, Subcontratación, ob. cit., p. 56 s. 
el resguardo de la vida y salud de estos trabajadores, ${ }^{36}$ con lo cual se quiso revertir los altos índices de accidentabilidad que existen en las áreas en las que predomina esta forma de subcontratación, como es el caso, por ejemplo, de la construcción. ${ }^{37}$

\subsection{La subcontratación de servicios personales o suministro de trabajadores}

Esta segunda clase de subcontratación, denominada también suministro de trabajadores o trabajo transitorio (en la terminología de la Ley $\mathrm{N}^{\circ}$ 20.123) que surge directamente como una consecuencia de los procesos de descentralización productiva es, sin duda, la variante más compleja y problemática de subcontratación laboral, ya que viene a alterar los elementos normales de una relación laboral al producir una fragmentación de la persona del empleador entre un empleador formal, que asume las obligaciones propias de esta parte del contrato de trabajo, en particular el pago de las remuneraciones y de las cotizaciones previsionales, pero sin recibir servicios del trabajador ni ejercer poder de dirección y, un empleador aparente, que no es parte del contrato de trabajo, pero que recibe y controla en sus propias instalaciones los servicios del trabajador. ${ }^{38}$ Se produce así una relación jurídica triangular, que rompe la bilateralidad que es propia de una relación laboral normal. ${ }^{39}$

Como ya se hiciera presente, hasta antes de la dictación de la Ley $\mathrm{N}^{\mathrm{o}} 20.123$ esta segunda forma de subcontratación laboral carecía de un reconocimiento expreso en la legislación laboral, ocasionando graves problemas de precariedad, por lo que su inclusión y regulación en la ley referida viene a ser la principal innovación realizada al CdT. En concreto, esta reforma laboral incorpora un Párrafo $2^{\circ}$ al nuevo Título VII del Libro I del CdT (artículos 183-F a 183-AE) en el que, en términos generales, se centra la regulación del suministro de trabajadores a partir de:

a) La definición y regulación de la actividad de las Empresas de Servicios Transitorios (EST) ${ }^{40}$

36 A esta materia se refieren los artículos 183-E del CdT y el nuevo artículo 66 bis de la Ley $\mathrm{N}^{\mathrm{o}} 16.744$ sobre accidentes del trabajo y enfermedades profesionales, incorporado por la Ley $\mathrm{N}^{\circ} 20.123$.

37 Sobre el particular: Palavecino, Claudio, Subcontratación, ob. cit., p. 78-80. Véase asimismo: el Decreto Supremo No 96 del Ministerio del Trabajo y Previsión Social, de fecha 14 de diciembre de 2006, que aprueba el reglamento para la aplicación del artículo 66 bis de la Ley $N^{\circ} 16.744$ sobre la gestión de seguridad y salud en el trabajo para obras, faenas o servicios en que presten servicios trabajadores sujetos a régimen de subcontratación (texto disponible en: www.mintrab.cl); Dirección del Trabajo, Paso a paso: Ley 20.123 Protección a la salud y seguridad de los trabajadores, documento disponible en: http://www.dt.gob.cl/1601/article-94372.html.

38 Ver: Ugarte Cataldo, José Luis, "Suministro de trabajadores y trabajo temporal. ¿Empresas sin trabajadores?”, Revista Laboral Chilena, junio 1998, p. 76 s.

39 Igual situación se establece a propósito de la regulación de esta materia en Alemania en el texto legal Gesetz zur Regelung der gewerbsmässigen Arbeitnehmerüberlassung en su edición actualizada del 31 de octubre de 2006. En detalle: Dieterich, Thomas; Hanau, Meter; Schaub, Günter, Erfurter Komentar zum Arbeitsrecht, ob. cit., p. 543.

40 El artículo 183-F letra a) del CdT define a las EST como: "toda persona jurídica, inscrita en el registro respectivo, que tenga por objeto social exclusivo poner a disposición de terceros denominados para estos efectos empresas 
La ley de subcontratación y la tutela de los derechos fundamentales de los trabajadores de servicios transitorios

con miras a identificarlas por medio de un registro público; establecer garantías y sanciones para asegurar su correcta actuación en el desarrollo de actividades de puesta a disposición de trabajadores; fijar su objeto social; como asimismo, delimitar su individualidad como un sujeto de derecho independiente desde el punto de vista económico y jurídico de las empresas a quienes presta servicios ${ }^{41}$ con el fin de terminar con falsas situaciones de subcontratación destinadas únicamente a abaratar costos laborales y a restringir el ejercicio de derechos individuales y colectivos. ${ }^{42}$

b) La definición y delimitación de responsabilidades de la Empresa Usuaria (EU), ${ }^{43}$ sujeto que, sin revestir la calidad formal de empleador respecto de los trabajadores suministrados, ejercerá en los hechos un verdadero rol de empleador, al recibir los servicios que éstos presten y controlarlos en su forma, tiempo y lugar de desarrollo, mediante el ejercicio de un auténtico poder de dirección. ${ }^{44}$ Por lo tanto, desde el punto de vista de la realización concreta de la actividad laboral será la EU la contraparte del trabajador, sin ser su empleador y sin llegar a asumir plenas responsabilidades en materia laboral y previsional como es propio de una relación laboral normal o típica. ${ }^{45}$

c) La regulación del contrato que se celebra entre la EST y la EU con el objeto de suministrar trabajadores, que podrá ser de naturaleza civil o comercial, y que se denomina contrato de puesta a disposición, destacando su carácter solemne ${ }^{46}$ y la determinación que se hace de su contenido, el que deberá indicar particularmente los puestos de trabajo para los que se

usuarias, trabajadores para cumplir en estas últimas, tareas de carácter transitorio u ocasional, como asimismo la selección, capacitación y formación de trabajadores, así como otras actividades afines en el ámbito de los recursos humanos."

$41 \quad$ Así lo dispone expresamente el nuevo artículo 183-I del CdT.

42 En detalle: Palavecino, Claudio, Subcontratación, ob. cit., p. 84-86.

43 El artículo 183-F letra b) del CdT define a la Usuaria como: "toda persona natural o jurídica que contrata con una empresa de servicios transitorios, la puesta a disposición de trabajadores para realizar labores o tareas transitorias u ocasionales, cuando concurra alguna de las circunstancias enumeradas en el artículo 183-Ñ de este código."

$44 \quad$ Así lo reconoce expresamente el artículo 183-X inciso 1, frase 1, del CdT al disponer que: "La usuaria tendrá la facultad de organizar y dirigir el trabajo, dentro del ámbito de las funciones para las cuales el trabajador fue puesto a su disposición por la empresa de servicios transitorios."

45 En efecto, el artículo 183-AB del CdT establece que la usuaria sólo será subsidiariamente responsable de las obligaciones laborales y previsionales que afecten a las EST a favor de los trabajadores de ésta. No obstante, esta disposición prescribe que la empresa usuaria asumirá una responsabilidad directa frente al cumplimiento de las normas de higiene y seguridad en el trabajo, en concordancia con lo previsto por el nuevo artículo 66 bis de la Ley $\mathrm{N}^{\mathrm{o}} 16.744$.

$46 \quad$ El artículo 183-N inciso 1 del CdT establece que el contrato de puesta a disposición deberá constar por escrito. Luego el inciso final de esta norma señala que: "La falta de contrato a escrito de puesta a disposición de trabajadores de servicios transitorios excluirá a la usuaria de la aplicación de las normas del presente Párrafo. En consecuencia, el trabajador se considerará como dependiente de la usuaria, vínculo que se regirá por las normas de la legislación laboral común ç, sin perjuicio de las demás sanciones que corresponda aplicar conforme a este Código." 
realiza, el tiempo de puesta a disposición de los trabajadores, el precio que se conviene por estos servicios y, sobre todo, las causales que se invocan para la contratación de servicios transitorios. En relación con esto último cabe resaltar que el artículo 183-Ñ del CdT señala de manera taxativa las situaciones que autorizan la celebración de este contrato, ${ }^{47}$ de tal manera que el suministro realizado fuera de los casos expresamente permitidos traerá como consecuencia, más allá de las sanciones administrativas por la contravención de esta normativa, que se considerará que el trabajador es dependiente directo de la EU, debiendo asumir ésta, al no existir subcontratación, todas las obligaciones que la ley le impone al empleador, según lo prescribe explícitamente el artículo 183-P el CdT.

d) La regulación de la particular relación laboral que se da entre la EST y el trabajador transitorio, ${ }^{48}$ la que se materializa en un nuevo tipo de contrato de trabajo, de carácter solemne, ya que debe celebrarse por escrito, denominado contrato de trabajo de servicios transitorios y que se define en el artículo 183-R del CdT como: "una convención en virtud de la cual un trabajador y una empresa de servicios transitorios se obligan recíprocamente, aquél a ejecutar labores específicas para una usuaria de dicha empresa, y ésta a pagar la remuneración determinada por el tiempo convenido." ${ }^{49}$

e) La regulación a partir del artículo $183-\mathrm{W}$ del CdT de la relación que se genera entre la EU y el trabajador de servicios transitorios que, sin poseer una carácter laboral, da lugar a una serie de derechos y obligaciones recíprocas ${ }^{50}$ que se explican por las particularidades de la forma, tiempo y lugar en que se prestan los servicios, apuntando, en último término, a materializar la deseada protección de estos trabajadores que inspira la normativa incorporada por la Ley $\mathrm{N}^{\mathrm{o}} 20.123$.

47 Sobre la materia: Palavecino, Claudio, Subcontratación, ob. cit., p. 87-89.

48 El artículo 183-F letra c) del CdT define al trabajador de servicios transitorios como: "todo aquel que ha convenido un contrato de trabajo con una empresa de servicios transitorios para ser puesto a disposición de una o más usuarias de aquélla, de acuerdo a las disposiciones de este Párrafo $2^{\circ}$."

49 En detalle: Palavecino, Claudio, Subcontratación, ob. cit., p 89 s.

50 En base a las normas incorporadas al CdT por la Ley $\mathrm{N}^{\circ} 20.123$ se puede concluir que son derechos y obligaciones de la EU las siguientes: a) Controlar la asistencia de los trabajadores transitorios (artículo 183-W); b) ejercer el poder de dirección respecto de los trabajadores transitorios dentro del ámbito de sus tareas (artículo 183-X); c) cumplir condiciones sobre jornada de trabajo, descansos, naturaleza y lugar de prestación de los servicios convenidas entre el trabajador y la EST (artículo 183-X); d) no poder exigir trabajo en jornada extraordinaria, salvo acuerdo entre el trabajador y la EST de acuerdo a las reglas generales de los artículos 30 y siguientes del CdT (artículo 183-X); e) asumir una responsabilidad subsidiaria por las obligaciones laborales y previsionales de las EST (artículo 183-AB); f) asumir una responsabilidad directa en el cumplimiento de las normas de higiene y seguridad (artículo 183- AB inciso 2). Por su parte, desde la perspectiva de la relación entre el trabajador transitorio con la EU destaca su derecho a la protección de su vida y salud con ocasión de la prestación de sus servicios (artículo 183-AB inciso 2 y artículo 66 bis de la Ley № 16.744), así como su obligación de sujetarse a las obligaciones y prohibiciones del reglamento interno de la usuaria (artículo 183-X inciso 1). 
La ley de subcontratación y la tutela de los derechos fundamentales de los trabajadores de servicios transitorios

Una vez descrita de manera general la forma en que la nueva normativa incorporada al CdT asume la regulación de la subcontratación de servicios personales, identificando a sus actores y los vínculos jurídicos que se generan entre ellos, pasaremos en las partes siguientes de este estudio a concentrarnos en uno sólo de los múltiples aspectos que tienen lugar en el desarrollo de esta relación triangular entre la EST, la EU y el trabajador transitorio, cual es el de la proyección de los derechos fundamentales de estos trabajadores respecto de la EST y, particularmente, en relación con la EU, quien, como ya se precisara, actúa como empleador sin serlo realmente, todo lo cual genera una serie de interrogantes no resueltas de manera íntegra por la actual legislación.

\section{Una nueva dimensión del derecho del trabajo: los derechos fundamentales y su proyección en la empresa}

A partir del reconocimiento de lo que la doctrina ha denominado la "ciudadanía en la empresa", esto es, la aceptación de que el espacio privado en el que se desarrollan las relaciones laborales - la empresa - no es un ámbito marginado del respeto, protección y ejercicio de aquellas garantías propias de todo ser humano por el sólo hecho de ser tal, se abre una nueva dimensión para la tutela de los derechos de los trabajadores. ${ }^{51}$ En concreto, se hace posible generar un cambio en la forma de entender las relaciones laborales al interior de la empresa, lo que permite, en palabras de Supiot, ${ }^{52}$ configurar dos facetas para la cuestión de las libertades públicas en la empresa. Por un lado, bajo su aspecto colectivo, las libertades públicas conducen a dibujar en el seno de la empresa áreas de autonomía que escapan al poder dirección del empresario (v. gr. el sindicato y la autonomía frente al empleador como atributo de la libertad sindical) y, por otro, bajo su aspecto individual, las libertades públicas en la empresa tienden a salvaguardar las libertades del trabajador de los excesos del vínculo de subordinación. Por tanto, este reenfoque de la situación laboral al interior de la empresa busca conciliar los intereses particulares de los actores sociales y las bases de una economía de libre mercado, con los principios y valores inspirados en la libertad, el respeto a la dignidad del ser humano, la equidad

51 Entre otros: Gamonal Contreras, Sergio, La ciudadanía en la empresa o los derechos fundamentales inespecíficos, Editorial Fundación de Cultura Universitaria, Montevideo, Uruguay, 2004; Melis, Christian, "Derechos fundamentales y empresas: apuntes para una configuración dogmático-jurídica", Anuario de Derecho del Trabajo y Seguridad Social Nr. 3/2004, Derechos Fundamentales. Homenaje al Profesor Patricio Novoa Fuenzalida, Sociedad Chilena de Derecho del Trabajo y de la Seguridad Social, p. 71 s.; Sáez, Felipe, "El reconocimiento de los derechos fundamentales al interior de la empresa en las reformas laborales", Boletín Oficial de la Dirección del Trabajo, noviembre 2001, p. 5 s.; Ugarte, José Luis, "Los derechos fundamentales y las relaciones laborales: en el mundo de las palabras", Anuario de Derecho del Trabajo y Seguridad Social Nr. 3/2004, Derechos Fundamentales. Homenaje al Profesor Patricio Novoa Fuenzalida, Sociedad Chilena de Derecho del Trabajo y de la Seguridad Social, p. 21 s.; Caamaño Rojo, Eduardo, El derecho a la no discriminación en el empleo, Editorial Lexis Nexis, Santiago, Chile, 2005.

52 Supiot, Alain, Crítica del Derecho del Trabajo, Colección Informes y Estudios № 11, Ministerio del Trabajo y Asuntos Sociales, Madrid, 1996, p. 176. 
y la igualdad de oportunidades implícitos en los derechos esenciales que la Carta Fundamental asegura a todas las personas, con lo cual es posible construir un modelo más justo y solidario de relaciones de producción y trabajo.

Es así, entonces, que salvo ciertas mínimas adaptaciones orientadas a compatibilizar los intereses de empleadores y trabajadores, la nueva configuración dogmática del Derecho del Trabajo permite concluir que los derechos fundamentales se proyectan durante todo el iter contractual laboral, con lo cual ha sido posible reconocer que la titularidad de derechos esenciales del trabajador en cuanto persona no es contrapuesta con su calidad de parte de un contrato de trabajo y, consecuentemente, se le debe garantizar la posibilidad de ejercerlos en el ámbito de la empresa y en el desarrollo concreto y material de la relación de trabajo. En efecto, como sostiene López, ${ }^{53}$ la relación laboral en que un empleador manda y un trabajador obedece, otorga al primero, en tanto jefe, facultades o poderes jurídicos para ordenar y dirigir la prestación contratada y, al segundo, en tanto subordinado, el deber de cumplir dichas órdenes. Se trata de un poder privado para dirigir el trabajo; un poder jurídico sobre la persona del trabajador sólo referido a la correcta realización del trabajo y no extensible a otros aspectos de la vida del trabajador, pues incluso respecto de la ejecución del trabajo no es ilimitado, ya que debe detenerse allí donde empiezan los derechos que éste detenta como persona. En consecuencia, el sometimiento remunerado a la autoridad de un empleador para ganarse la vida no impide, limita ni atenúa los derechos fundamentales del trabajador.

Por lo anterior, la nueva concepción del Derecho del Trabajo surgida a partir de la aceptación de la eficacia horizontal, vale decir, entre particulares, de los derechos fundamentales ha permitido que se reconozcan esas libertades al interior de la empresa. Tal reconocimiento ha consistido, ante todo, en evitar que la autoridad patronal usurpe las libertades de fuera de la empresa, circunscribiendo el campo de ejercicio de la misma al ámbito contractual, es decir, a la ejecución del contrato de trabajo, para lo cual se establece la obligación de los empresarios de no extender su poder de dirección a la vida extraprofesional del trabajador, ya se trate de su vida privada o de su vida pública. ${ }^{54}$ De esta manera, el paulatino y decidido proceso de constitucionalización del Derecho del Trabajo ha contribuido a introducir elementos de juicio que permiten resolver la tradicional tensión entre el poder privado entregado al empleador y el debido respeto de los derechos fundamentales extra laborales del trabajador. A su vez, este proceso ha permitido comenzar a resolver la contradicción entre el reconocimiento constitucional de una serie de derechos fundamentales de la persona y la evidente constatación empírica de su negación o limitación en el ámbito concreto de la empresa. Se pretende así dar una respuesta a una serie de problemas prácticos referidos a la falta de un adecuado reconocimiento de los

\footnotetext{
53 López, Diego, "Los derechos fundamentales en el trabajo: garantía de libertad y dignidad de las personas que trabajan," Temas Laborales de la Dirección del Trabajo 22, noviembre 2004, p. 1.

54 En este sentido, Supiot, Alain, Crítica del Derecho del Trabajo, ob. cit., p. 185.
} 
La ley de subcontratación y la tutela de los derechos fundamentales de los trabajadores de servicios transitorios

derechos fundamentales de la persona en la empresa y a la ulterior reticencia del Derecho del Trabajo tradicional en este sentido, que implicaba darle a la empresa un carácter autárquico, con sus propias leyes y autoridades internas.

En resumen, la noción de ciudadanía en la empresa surge a partir del reconocimiento jurisprudencial, doctrinal y legal de que la empresa no es un espacio entregado única y soberanamente al ejercicio de los poderes empresariales, sino que es un ámbito en el que también tiene cabida y pleno reconocimiento la ciudadanía de los trabajadores, esto es, la titularidad de un conjunto de derechos fundamentales emanados de su condición de persona, particularmente, derechos civiles y políticos que en cierta forma quedaban amagados en la relación laboral, ya sea por la necesidad de una mejora urgente de las condiciones económicas y de trabajo o por efecto de la exacerbación de la potestad de mando del empleador. ${ }^{55}$ Así, entonces, la conversión de los derechos fundamentales de contenido no laboral (v. gr. libertad de expresión, derecho a la igualdad de trato y a la no discriminación, libertad religiosa, etc.) en verdaderos derechos fundamentales laborales tiene lugar por una doble y simultánea vía: por una parte, en cuanto son trabajadores los sujetos a los que les corresponde la titularidad del derecho y, por otra, porque el derecho se ejerce en una relación jurídica laboral.

Por todo lo expuesto se puede entender que, en la actualidad, la protección del trabajador se materializa por dos cauces complementarios entre sí. Por un lado, se mantiene la tutela tradicional contenida en el ordenamiento jurídico laboral, manifestada, en el ámbito de las relaciones contractuales individuales, en el otorgamiento de un conjunto de derechos mínimos irrenunciables a favor del trabajador que limitan la autonomía de la voluntad de las partes del contrato de trabajo y, en el ámbito de las relaciones colectivas, mediante el reconocimiento de la autotutela colectiva expresada en el ejercicio de la libertad sindical. Por otro lado, la aceptación de la ciudadanía laboral agrega todo el abanico de protección a la esfera individual de las personas que conllevan los derechos fundamentales consagrados tanto en la Constitución Política de la República, como en los instrumentos internacionales sobre derechos humanos ratificados por Chile, los que se van a erigir como un límite natural al ejercicio de los poderes empresariales, como a su vez, en valores orientadores e integradores de la normativa laboral tradicional. ${ }^{56}$

55 Gamonal, Sergio, La ciudadanía en la empresa o los derechos fundamentales inespecíficos, ob. cit., p. 14. Véase también: Mélis, Christian, "En torno al contrato de trabajo y los derechos fundamentales", Boletín Oficial de la Dirección del Trabajo, No 148, 2001, p. 8 s. (Parte I), № 149, 2001, p. 5 s. (Parte II); Sáez, Felipe, "El reconocimiento de los derechos fundamentales al interior de la empresa en las reformas laborales", Boletín Oficial de la Dirección del Trabajo, noviembre 2001, p. 5 s.

56 Esta visión encuentra un claro fundamento en el actual texto del artículo 5 del CdT, en el cual es posible constatar que la protección al trabajador derivada del respeto debido a sus derechos fundamentales (inciso1) se superpone y complementa a la protección tradicional que se le reconoce en cuanto trabajador, mediante la declaración de irrenunciabilidad de los derechos mínimos que le otorga la legislación laboral (inciso 2). 
Ahora bien, Chile no ha estado al margen de esta nueva corriente de pensamiento y es así como en el último tiempo la concepción de la ciudadanía en la empresa ha encontrado una decidida aceptación por la doctrina iuslaboralista nacional y, de manera muy destacada, por los dictámenes de la Dirección del Trabajo, ${ }^{57}$ los que han hecho posible la configuración de una verdadera jurisprudencia sobre el tema y, en concreto, han llevado al terreno práctico y cotidiano de las relaciones laborales la validación de la eficacia de los derechos fundamentales en las relaciones entre particulares. ${ }^{58}$ Sin perjuicio de lo anterior, no puede desconocerse que las principales reformas legales introducidas al ordenamiento jurídico laboral desde hace algún tiempo a esta parte, han plasmado también normativamente y en forma explícita el reconocimiento de los derechos fundamentales de los trabajadores en cuanto personas en el desarrollo de la actividad laboral, ${ }^{59}$ erigiéndose estas garantías como un claro límite al ejercicio de las facultades que la misma ley reconoce al empleador, ${ }^{60}$ según lo dispone expresamente el actual artículo 5 inciso 1 del Código del Trabajo. ${ }^{61}$ En todo caso, cabe destacar que estos

57 Véase: Caamaño Rojo, Eduardo, "La eficacia de los derechos fundamentales en las relaciones laborales y su reconocimiento por la Dirección del Trabajo", Revista de Derecho, Pontificia Universidad Católica de Valparaíso, Vol. XXVII, Semestre I, 2006, p. 19 s.

58 Una menor incidencia en el desarrollo de esta temática ha tenido la jurisprudencia judicial chilena. Afortunadamente, en el último tiempo los tribunales han comenzado a incorporar esta visión en diversos fallos ante situaciones en las que se ha planteado una vulneración de derechos fundamentales en el trabajo. Véase, entre otras, sentencia pronunciada por la Corte de Apelaciones de de Puerto Montt de fecha 30 de septiembre de 2005, causa rol No 156-2005, sobre el recurso de protección interpuesto a favor de los trabajadores afiliados a los sindicatos de la empresa Acqua Chile por la implementación de medidas de control a través de cámaras de video; sentencia de la Corte de Apelaciones de Valdivia, de fecha 6 de septiembre de 2006, causa rol No 665 2006, confirmada por la Corte Suprema con fecha 10 de octubre de 2006, causa rol $N^{\circ} 4858-2006$, en recurso de protección interpuesto por una funcionaria de la Municipalidad de Valdivia basado en conductas de acoso laboral o mobbing.

59 Claros ejemplos en este sentido son: el artículo 2 del CdT que refuerza el respeto a la dignidad del trabajador y tipifica como ilícitos laborales al acoso sexual y a los actos de discriminación; el artículo 153 inciso 2 del CdT que potencia al reglamento interno como un instrumento que debe contribuir a garantizar un ambiente laboral digno y de mutuo respeto entre los trabajadores; el artículo 154 bis sobre la obligación del empleador de mantener reserva de toda la información y datos privados del trabajador a que tenga acceso (norma reiterada por el nuevo artículo 183-Y del CdT); el artículo 154 inciso final que fija criterios para que la aplicación de medidas de control en el reglamento interno sean acordes con el respeto a la dignidad del trabajador y; el artículo 194 inciso final del CdT que prohíbe los test de embarazo.

60 Véase: Melis, Christian, "Derechos fundamentales y empresas: apuntes para una configuración dogmáticojurídica", ob. cit., p. 105-106.

61 Esta función de los derechos fundamentales ha sido reconocida por la jurisprudencia de la Dirección del Trabajo desde antes de la reforma legal introducida por la Ley $N^{\circ} 19.759$. Es así, como el dictamen $N^{\circ} 287 / 014$, de fecha 11 de enero de 1996, estableció que: “...mientras el sistema jurídico dota al empleador de lo que la doctrina llama el poder de dirección y de disciplina, esto es, de la facultad para dirigir y mantener el orden dentro de la empresa, que de alguna manera es manifestación de los derechos constitucionales de propiedad y de la libertad para desarrollar cualquier actividad económica, dicha facultad se encuentra jurídicamente limitada por las garantías constitucionales dirigidas a proteger la dignidad y honra de las personas." Posteriormente, la Dirección del Trabajo ha precisado este criterio a través del dictamen $\mathrm{N}^{\circ}$ 2856/162, de fecha 30 de agosto de 2002, en el que se fija el sentido y alcance del artículo 5 inciso 1 del CdT. 
La ley de subcontratación y la tutela de los derechos fundamentales de los trabajadores de servicios transitorios

límites impuestos a las facultades empresariales operarán en forma negativa, esto es, como prohibición de cualquier actitud que vulnere estas libertades, ${ }^{62}$ pero no obligan al empleador a modificar su estructura productiva al tenor de los derechos fundamentales de sus trabajadores para facilitar su ejercicio. ${ }^{63}$

A continuación, se efectuará un análisis sobre las implicancias particulares que los derechos fundamentales tienen en las relaciones que se generan entre los actores de la relación laboral triangular que particulariza al suministro de trabajadores. Con todo, estimamos pertinente recordar con ocasión de esta materia que es indudable que la eficacia de los derechos fundamentales se materializa también sin mayores complejidades dogmáticas respecto de la subcontratación de bienes y servicios de la que se ocupan los artículos 183-A a 183-E del CdT, toda vez que, de acuerdo a lo ya precisado, en esta particular forma de tercerización no se ven alterados los supuestos ni los elementos definidores de una relación laboral normal fundada en el contrato individual de trabajo que define el artículo 7 del CdT, siendo por tanto el único empleador la empresa contratista o la subcontratista, en su caso. Por ello, tiene plena aplicación el ya referido artículo 5 inciso 1 del $\mathrm{CdT}^{64}$ que reconoce la función limitadora del poder de dirección que produce el necesario respeto de los derechos fundamentales de los trabajadores. Además, esta afirmación se ve respaldada por lo dispuesto en el nuevo artículo 183-E conforme al cual: "Sin perjuicio de los derechos que se reconocen en este Párrafo $1^{\circ}$ al trabajador en régimen de subcontratación, respecto del dueño de la obra, empresa o faena, el trabajador gozará de todos los derechos que las leyes del trabajo le reconocen en relación con su empleador."

Entre estos derechos que se reconoce al trabajador está naturalmente el de poder hacer valer sus derechos fundamentales en el desarrollo de su actividad laboral, como asimismo, el poder impetrar su protección por la vía jurisdiccional mediante el procedimiento que incorporó la Ley $\mathrm{N}^{\circ} 20.087$ a partir del artículo 485 del CdT, una vez que el nuevo proceso laboral pueda entrar definitivamente en vigencia.

62 En esta misma línea de pensamiento, López manifiesta que: “Todos estos derechos operan como una limitación de los poderes empresariales respecto a la ejecución del trabajo humano; garantizan una contrapartida humana al acuerdo de trabajo por dinero: al considerar al trabajador un sujeto de derechos, necesariamente debe asegurarse que los derechos fundamentales de la persona humana no se pierdan o disminuyan por el hecho de ponerse bajo las órdenes de quien compra un trabajo para utilizarlo en su propio provecho. El acuerdo económico de remuneración a cambio de trabajo no hace menos persona o ciudadano al trabajador. Hay pues, valores no patrimoniales en el intercambio económico del trabajo; el trabajador es titular de derechos y su trabajo no puede utilizarse sino respetando la dignidad humana del prestador. Los derechos fundamentales de la persona humana no pierden vigencia en una relación de trabajo; antes bien, garantizan que los trabajadores no se vean reducidos sólo a una función productiva y económica.” Véase: López, Diego, "Los derechos fundamentales en el trabajo", ob. cit., p. 2.

63 Gamonal, Sergio, La ciudadanía en la empresa o los derechos fundamentales inespecíficos, ob. cit., p. 23.

64 Véase el dictamen de la Dirección del Trabajo $N^{\circ}$ 2856/162 de 30 de agosto de 2002, que fija el sentido y alcance del artículo 5 inciso 1 del CdT. 


\section{La vigencia de los derechos fundamentales en la subcontratación de servicios personales}

\subsection{Antecedentes del artículo 183-y del Código del Trabajo}

Siendo coherente con la reciente evolución del Derecho del Trabajo chileno en la que cobra una clara relevancia la promoción del respeto de los derechos fundamentales de los trabajadores, la Ley $\mathrm{N}^{\mathrm{o}} 20.123$ incorporó el artículo $183-\mathrm{Y}$ del CdT, ${ }^{65}$ mediante el cual la ya referida temática de la ciudadanía en la empresa es situada en el plano de la subcontratación de servicios personales, vale decir, respecto de una especial modalidad de contratación laboral caracterizada por su trilateralidad, lo cual viene a introducir nuevos elementos para dimensionar el alcance efectivo que pueden llegar a tener las garantías constitucionales de los trabajadores en el plano laboral.

En lo que respecta la historia del establecimiento de esta disposición en el curso de la tramitación de la Ley $\mathrm{N}^{\circ} 20.123$ en el Congreso Nacional, cabe hacer presente que el proyecto enviado originalmente por el Ejecutivo el año 2002 con el que se retomó la discusión sobre la subcontratación suspendida el año 2001, nada señalaba respecto de la aplicabilidad de los derechos fundamentales en el suministro de trabajadores. En particular, el artículo 183-Y del CdT tiene su antecedente directo en las indicaciones que presentaran los Senadores Parra y Ruiz De Giorgio durante el desarrollo del primer trámite legislativo ante el Senado, ${ }^{66}$ ocasión en la que se propuso la incorporación del artículo 152-AB (que luego en el proyecto pasa a ser el artículo 152-Z) el cual tenía el mismo tenor que el actual artículo 183-Y del CdT. Ahora bien, es interesante destacar que al momento de la discusión de este artículo en dicha instancia legislativa se señaló por el Senador Sergio Fernández, que esta norma no sería necesaria, ya que a su juicio siempre deben respetarse las garantías constitucionales, no sólo de los trabajadores, sino de todas las personas. Por su parte, los representantes del Ejecutivo señalaron que los incisos de este precepto equivalen a lo consagrado en las normas generales del CdT, a saber, en sus artículos 5 y 154 bis, respectivamente, pero lo relevante es que el artículo $152 \mathrm{AB}$ establecería las obligaciones del caso para la usuaria, que en este tipo de contratos no es el empleador del trabajador en cuestión, por lo que en la norma propuesta hay envuelto un fuerte sentido promocional de los derechos fundamentales. En definitiva, puesto luego en votación el artículo 152 AB fue aprobado unánimemente, aunque con la salvedad del Senador Fernández de estimar innecesaria esta norma.

Esta disposición del CdT prescribe que: "El ejercicio de las facultades que la ley le reconoce a la usuaria, tiene como límite el respeto a las garantías constitucionales de los trabajadores, en especial cuando pudieran afectar la intimidad, la vida privada o la honra de éstos. (inciso 1) La usuaria deberá mantener reserva de toda la información y datos privados del trabajador a que tenga acceso con ocasión de la relación laboral. (inciso 2)

66 Véase el primer informe de la Comisión del Trabajo del Senado, p. 169, del documento que contiene la historia de la Ley $\mathrm{N}^{\mathrm{o}} 20.123$, disponible en el sitio web de la Biblioteca del Congreso Nacional (www.bcn.cl). 
La ley de subcontratación y la tutela de los derechos fundamentales de los trabajadores de servicios transitorios

Posteriormente, vuelve a presentarse una indicación - por parte de los Senadores Fernández, Romero y Canessa - para eliminar la norma del artículo $152-Z^{67}$ por estimarla innecesaria ya que existía otra norma genérica en el CdT que promovía el respeto de estas garantías. Afortunadamente, en nuestra opinión, la Comisión del Trabajo del Senado rechazó esta indicación, siendo interesante destacar a este respecto el comentario del Senador Parra, quien al fundamentar su voto de rechazo a esta indicación señaló que: “.... pesar de que podría estimarse que las normas constitucionales y legales que regulan estas materias hacen innecesario este precepto, siempre es bueno consagrar estos aspectos de manera expresa, especialmente considerando que aluden a obligaciones que asume la usuaria, que no es parte del contrato de trabajo de servicios temporarios." 68 Con todo, cierto grupo de Senadores (nos referimos a los señores Fernández, Canessa, Arancibia, Cariola, Chadwick, Coloma, Stange, Romero y Novoa) no quedó conforme con este acuerdo y luego en la discusión en sala de este proyecto en el Senado, insistieron en su propuesta de retirar la norma en comento por innecesaria y reiterativa ${ }^{69}$.

En esta ocasión, tampoco se generó mucho debate sobre la materia, limitándose el Senador Viera Gallo a manifestar que: “...con este artículo o sin él, resulta obvio que, si hay involucradas garantías constitucionales, deben ser respetadas. Y, en lo que respecta al inciso segundo, lo propio ha de ocurrir con la ley de protección a los datos privados de las personas. O sea, es algo elemental. Ahora, si se quiere reafirmar lo anterior, está bien incluirlo en el proyecto. Pero si alguien desea suprimirlo, que no crea que por eliminarlo desaparecerán las obligaciones pertinentes." Ante esta observación, el Senador Fernández insistió que la opinión de retirar la norma tenía únicamente un fundamento de técnica legislativa, con lo que da a entender que no se opone al contenido de la norma. En último término, los promotores de esta indicación volvieron a retirarla y la norma se mantuvo con el tenor que hoy tiene el artículo 183-Y del CdT, sin que se produjeran posteriormente ni en el Senado ni en la Cámara de Diputados discusiones sobre esta disposición, por lo que se mantuvo en el texto legal que luego fue promulgado como Ley $\mathrm{N}^{\circ} 20.123$, con la única particularidad de ver alterada su ubicación pasando del número 152 al 183 y de la letra $\mathrm{Z}$ a la letra $\mathrm{Y}$.

Teniendo en cuenta estos antecedentes derivados del análisis de la historia de la Ley $\mathrm{N}^{\mathrm{o}}$ 20.123 no cabe sino mostrarse conforme y satisfecho de que la norma del artículo 183-Y haya podido ser incorporada al CdT luego de los diversos vaivenes que precedieron a la dictación de esta ley, ya que ello viene a posicionar fuertemente el tema de la vigencia efectiva de los derechos fundamentales en el ámbito de las relaciones laborales atípicas, por tanto, más allá de lo que constituye una relación laboral típica o normal concebida a partir de la óptica tradicional

Véase: Boletín de Indicaciones en Historia de la Ley No 20.123, ob. cit, p. 246. Segundo Informe de la Comisión del Trabajo del Senado, Historia de la Ley N 20.123, ob. cit, p. 283.

Historia de la Ley No 20.123, ob. cit, p. 411-412. 
del Derecho del Trabajo. ${ }^{70}$ Con todo, cabe señalar que la posición disidente liderada por el Senador Fernández no carecía de lógica y de fundamento, pues resulta evidente que aún sin norma expresa las garantías constitucionales irradian su eficacia protectora a todas las relaciones entre particulares. ${ }^{71}$ Sin embargo, creemos que frente a la configuración de una relación de carácter triangular, que es propia y definidora del suministro de trabajadores, la explicitación del debido respeto de los derechos fundamentales debido por la usuaria al trabajador transitorio viene a evitar algunos problemas interpretativos mayores acerca de su real grado de eficacia, dado que la usuaria no es verdaderamente empleadora, con lo cual se excluyen sin más las interpretaciones literales - tan queridas en nuestro medio nacional - que habrían podido hacerse del artículo 5 inciso 1 del CdT y que habrían podido significar una exclusión de la ciudadanía laboral en el ámbito de los servicios transitorios. A su vez, es digno de destacarse que el artículo 183-Y viene a dar una señal explícita tanto a los trabajadores, empleadores y empresas, en el desarrollo concreto de la prestación, recepción y control de los servicios, como a los jueces, al momento de tener que resolver un conflicto, y a la Dirección del Trabajo, al fiscalizar el debido cumplimiento de la nueva normativa sobre subcontratación, de la inclusión en la esfera protectora de los derechos fundamentales del trabajador transitorio, contribuyendo así, al menos en el plano teórico, a reforzar más aún la protección que le confiere la actual legislación laboral.

No obstante lo anterior, no se puede perder de vista que el actual artículo 183-Y del CdT presenta una serie de interrogantes acerca de la incidencia efectiva que tendrán los derechos fundamentales extra laborales que se le deben respetar al trabajador transitorio, lo que es consecuencia de la redacción genérica de la norma, la que viene sólo a reproducir en su inciso 1 lo dispuesto por el artículo 5 inciso $1 \mathrm{del} \mathrm{CdT} \mathrm{y,} \mathrm{en} \mathrm{su} \mathrm{inciso} \mathrm{2,} \mathrm{lo} \mathrm{preceptuado} \mathrm{por} \mathrm{el} \mathrm{artículo}$ 154 bis del mismo cuerpo legal. Es por eso, entonces, que en los acápites siguientes se tratará aportar algunas ideas y elementos de juicio al respecto, lo que, atendido el carácter triangular propio de la subcontratación de servicios personales, se efectuará desde la perspectiva de los diversos lados que conforman este triángulo de relaciones jurídicas entre la EST, la EU y el trabajador transitorio.

\subsection{Proyección de los derechos fundamentales en la relación entre la empresa de servicios transitorios y el trabajador}

Según ya se ha tenido oportunidad de establecer en el curso de este estudio, la EST es la

70 Sobre la materia: Caamaño Rojo, Eduardo, "Las transformaciones del trabajo, la crisis de la relación laboral normal y el desarrollo del empleo atípico", ob. cit., p. $25 \mathrm{~s}$.

71 Claros fundamentos normativos en este sentido son los artículos 6 inciso 2, 19 y 20 de la Constitución Política de la República. Véase: Caamaño Rojo, Eduardo, El derecho a la no discriminación en el empleo, ob. cit., p. 25 s.; Lizama Portal, Luis; Ugarte Cataldo, José Luis, Interpretación y derechos fundamentales, Editorial Jurídica Cono Sur, Santiago, Chile, 1998, p. 169. 
La ley de subcontratación y la tutela de los derechos fundamentales

de los trabajadores de servicios transitorios

contraparte empleadora del trabajador transitorio, en virtud de la relación jurídica que se constituye entre ellas a partir de la suscripción del contrato de trabajo de servicios transitorios definido por el artículo 183-R del CdT. Por esta razón, entonces, es obvio que el empleador estará en situación de tener que respetar los derechos fundamentales del trabajador en cualquiera de las tres etapas del iter contractual laboral, vale decir, al momento de su selección y contratación, durante la vigencia de la relación laboral y al momento de ponerle término.

Con todo, pueden presentarse algunas situaciones especiales a este respecto que merecen un comentario particular. Es así que si nos centramos en la primera etapa del iter contractual no se puede desconocer que es un ámbito en el que se manifiesta fuertemente la libertad de contratación del empresario, la que en su ejercicio podría entrar en conflicto con algunos derechos fundamentales, tales como el derecho a la no discriminación en el empleo, el derecho a la intimidad y, en general, el respeto a la vida privada de los postulantes a un puesto determinado, sin perjuicio, por ejemplo, de otros derechos de enorme significación laboral, como la libertad sindical. Por ello, en este plano resulta imperioso aplicar criterios que permitan un equilibrio de intereses y evitar conflictos de estos derechos, como a su vez, de un adecuado procedimiento de tutela en caso de materializarse una lesión a los derechos de la persona que está participando en un proceso selección. Si vinculamos lo anterior con nuestra realidad laboral en Chile, no cabe duda que el tema de la discriminación en el empleo es uno de los más dramáticos y sensibles. Lamentablemente, no se pueden presentar noticias alentadoras para los trabajadores transitorios en este plano, pues el procedimiento de tutela aprobado por la Ley $\mathrm{N}^{\circ} 20.087$ que representaba la esperanza para poner término a la insuficiencia del actual ordenamiento jurídico laboral sobre la materia, ${ }^{72}$ excluyó expresamente, producto de la intervención del Congreso Nacional, la aplicación de este mecanismo de protección jurisdiccional de los derechos fundamentales a las vulneraciones que puedan tener antes de la constitución de una relación laboral. En consecuencia, la eficacia de esta garantía constitucional o de otras que puedan verse afectadas en esta fase del iter contractual seguirá siendo relativa o derechamente ninguna, con lo cual se continuarán perpetuando en nuestro país la discriminación en el acceso al empleo ${ }^{73}$ y otras lesiones de derechos fundamentales producto de procesos de selección invasivos de la esfera individual y privada de la persona del trabajador.

Por otra parte, desde la perspectiva de una relación laboral ya constituida, también se presentan algunas situaciones especiales respecto de la vinculación que existe entre la EST y el trabajador transitorio, pues el artículo 5 inciso 1 del CdT que reconoce la función limitadora de

En detalle: Caamaño Rojo, Eduardo, El derecho a la no discriminación en el empleo, ob. cit., p. 107 s. Para comprobar empíricamente esta desoladora realidad basta revisar las ofertas de empleo que se publican los fines de semana en los principales periódicos del país, o bien, diariamente en internet, en los que abundan exigencias discriminatorias tales como: contar con buena presencia, cumplir con requisitos de edad, presentar certificados de antecedentes comerciales para cargos que no implican manejo de dinero o presentar un curriculum con una fotografía reciente. 
los derechos fundamentales frente al ejercicio del poder de dirección no resultaría directamente aplicable, ya que la EST es un mero empleador formal, contraparte del contrato, pero no recibe los servicios ni cuenta con poder de dirección para conducir la prestación de éstos, toda vez que su intervención en la relación laboral se limita a la de un mero intermediador. Lo mismo puede decirse respecto de la aplicación de medidas de control, limitadas por la necesidad de respetar los derechos fundamentales del trabajador, según lo señala expresamente el artículo 154 inciso final del CdT, pues estas disposiciones tendientes a verificar, en general, el correcto cumplimiento de las obligaciones del trabajador transitorio serán ejercidas por la EU, quien no detenta la calidad jurídica de empleador. Con todo, es posible encontrar otras disposiciones en las que sí se manifiesta la incidencia del respeto de los derechos fundamentales en este plano del análisis, como es la norma del artículo 154 bis que obliga a la EST, en su calidad de empleadora, a mantener reserva de toda la información y datos privados del trabajador a que tenga acceso con ocasión de la relación laboral. Sin perjuicio de lo anterior, como lo plantea Gamonal, ${ }^{74}$ es indudable que el deber general de respetar los derechos fundamentales de los trabajadores operará "en negativo" respecto de las facultades patronales como la prohibición de cualquier actitud que vulnere estas libertades.

A su vez, teóricamente, se puede proyectar en la relación jurídica entre el trabajador transitorio y la EST la incidencia de la libertad sindical y la posibilidad de ejercer los derechos fundamentales asociados a ella, como es el caso del derecho de sindicación, el derecho a negociar colectivamente y la huelga, los cuales contarán en el futuro, a partir del momento en que entre en vigencia la reforma procesal laboral introducida por la Ley $\mathrm{N}^{\circ} 20.087$, con un renovado y más eficaz procedimiento de tutela que suplirá las deficiencias de las actuales disposiciones de los artículos 292 y 389 del CdT en materia de prácticas antisindicales y desleales. ${ }^{75}$ No obstante, desde un punto de vista más práctico puede resultar irrelevante el reconocimiento de estos derechos por las dificultades obvias que presenta la real alternativa de constituir un sindicato, pensando, por ejemplo, que los trabajadores transitorios no tendrán la calidad de trabajadores permanentes de la EST, sino que serán contratados en función de un determinado contrato de puesta a disposición de trabajadores y que, una vez cesado éste, terminarán sus contratos de trabajo. Por tal motivo, como se planteará más adelante se necesitan cambios más profundos para alcanzar una promoción más plena de la libertad sindical.

Para concluir este acápite, cabe resaltar la incidencia que el debido respeto de los derechos fundamentales tiene al momento del término de la relación laboral entre la EST y el trabajador

74 Gamonal Contreras, Sergio, La ciudadanía en la empresa o los derechos fundamentales inespecíficos, ob. cit., p. 23.

75 Sobre la materia: Caamaño Rojo, Eduardo, "La tutela jurisdiccional de la libertad sindical", Revista de Derecho de la Facultad de Ciencias Jurídicas y Sociales, Universidad Austral de Chile - Valdivia, volumen XIX, julio 2006, p. 77 s. 
La ley de subcontratación y la tutela de los derechos fundamentales de los trabajadores de servicios transitorios

transitorio, lo que - idealmente a partir de marzo de 2008 - se traducirá en una tutela especial frente a los despidos con vulneración de las garantías constituciones o frente a los despidos discriminatorios, de conformidad con las nuevas disposiciones del artículo 489 del CdT, las que refuerzan el derecho a resarcimiento del trabajador, más allá de las meras indemnizaciones por término de contrato, en vistas a reparar de manera más integral la vulneración del derecho fundamental. No obstante, el afán de protección plena no llegó demasiado lejos en el nuevo procedimiento de tutela, pues se sacrifica la nulidad del despido y la vuelta al estado anterior al de la vulneración del derecho, y en ambos supuestos de despido con lesión de derechos fundamentales se establece un sistema de indemnización previamente tasada por el legislador, sin perjuicio de una opción de reincorporación en los supuestos más graves, la que con todo carece de atractivos y podría dar lugar a un justo temor de sufrir hostigamientos u acosos morales en el empleo, ${ }^{76}$ lo que desincentivará a los trabajadores frente a la alternativa cierta y segura de obtener una indemnización. Encontramos en esta materia, por tanto, una nueva manifestación del carácter transaccional de las normas procesales aprobadas, fruto de una negociación política y de las presiones de ciertos sectores empresariales, las que, en casos como estos, contribuyen a una grave distorsión del sentido jurídico original de la reforma técnicamente ideada. ${ }^{77}$

\subsection{Proyección de los derechos fundamentales en la relación entre la empresa usuaria y el trabajador transitorio}

En base a lo ya analizado se desprende que será en el plano de la relación jurídica entre la EU y el trabajador transitorio donde se manifestará con mayor realce el efecto de irradiación de los derechos fundamentales inespecíficos, incorporando una nueva dimensión de protección a la persona del trabajador transitorio que será directamente complementaria de las normas especiales que sobre esta clase de subcontratación contiene la Ley $\mathrm{N}^{\circ} 20.123$. En efecto, será la EU, sin ser empleadora, quien recibirá los servicios del trabajador transitorio y quien dirija y controle su actividad al interior de la empresa, según lo dispone de manera expresa el artículo 183-X del CdT. Esto origina que el trabajador transitorio se encuentre en una especial posición de sujeción frente a la EU, con quien no le une vínculo contractual alguno, sino una situación de hecho puntual, cual es la circunstancia de tener que prestar servicios para ella. Esto último adquiere un mayor énfasis si se considera que el trabajador transitorio quedará también sujeto al reglamento interno de la usuaria, conforme a lo prescrito por el artículo 183-X inciso 1, frase 2. Es así, como la ausencia de condiciones particulares referidas a la situación del trabajador en la EU, salvo las generales que contiene el contrato de puesta a disposición en materia de jornada

\footnotetext{
76 Sobre la materia: Gamonal Contreras, Sergio, Prado López. Pamela, El mobbing o acoso moral laboral, Editorial Lexis Nexis, Santiago, Chile, 2006.

77 En igual sentido: Ugarte Cataldo, José Luis, "Los derechos fundamentales del empleador: el nuevo procedimiento de tutela laboral", Colección Ensayos Jurídicos № 2, Facultad de Derecho, Universidad Alberto Hurtado, 2006, p. 35.
} 
de trabajo, ${ }^{78}$ descansos, la naturaleza de los servicios o el lugar en que deben prestarse, genera una suerte de zona gris propicia a los excesos del control de la actividad laboral por la EU, todo lo cual puede repercutir negativamente en la situación personal y profesional del trabajador. Además, las nuevas fórmulas de organización del trabajo suelen llevar aparejado un desdibujamiento de las fronteras entre la vida profesional y personal de los trabajadores, por lo que las posibilidades de que el control empresarial afecte a facetas de esta última aumentan considerablemente. ${ }^{79}$

Es por esta razón, entonces, que se incorpora la norma del artículo 183-Y del CdT como una proyección particular del artículo 5 inciso 1 del mismo cuerpo legal, en orden a posicionar claramente que estas potestades con las que actuará la EU frente al trabajador encuentran su límite natural en el debido respeto de los derechos fundamentales de éste.

En relación con la eficacia normativa de la disposición contenida en el artículo 183 Y, cabe hacer presente que el dictamen de la Dirección del Trabajo No 2856/162, de fecha 30 de agosto del 2002, emitido con el fin de precisar el sentido y alcance del inciso 1 del artículo 5 del CdT y que resulta naturalmente aplicable al supuesto que nos ocupa, señala que esta norma “...está revestida de un indudable valor normativo y dotada de una verdadera fuerza expansiva que debe impregnar la interpretación y aplicación de las normas jurídicas en base al principio favor libertatis, esto es, en un sentido que apunte a dar plena vigencia a los derechos fundamentales de la persona en el ámbito laboral". Por lo tanto, a juicio de la Dirección del Trabajo, el artículo 5 inciso 1 del CdT constituye un componente estructural básico del contenido material de nuestro sistema normativo laboral. En este sentido, de acuerdo con el dictamen, se puede afirmar con rotundidad que, de conformidad a las normas constitucionales y legales, los derechos fundamentales actúan en nuestro sistema jurídico-laboral como verdaderos ejes modeladores y conformadores de la idea de la ciudadanía en la empresa.

De igual manera, en concordancia con el referido dictamen de la Dirección del Trabajo, habría que concluir que, en todo caso, los derechos fundamentales reconocidos al trabajador transitorio en cuanto persona no son absolutos y reconocen como límites otros bienes u otras garantías constitucionalmente protegidas, así como también, la moral, el orden público y el bien común. Por lo mismo, en el ejercicio de un derecho fundamental puede producirse un conflicto con otros derechos o bienes constitucionalmente protegidos, el que se ha de resolver mediante la utilización de mecanismos de ponderación en clave constitucional, ${ }^{80}$ puesto que el

78 De acuerdo con el artículo $183-\mathrm{W}$ inciso 1 del CdT: "Será obligación de la usuaria controlar la asistencia del trabajador de servicios transitorios y poner a disposición de la empresa de servicios transitorios copia del registro respectiva."

79 En este sentido: Fernández Villazón, Luis, Las facultades empresariales de control de la actividad laboral, Editorial Aranzadi, Navarra, España, 2003, p. 14.

80 En detalle sobre el tema de la colisión de derechos fundamentales y la ponderación judicial: Ugarte Cataldo, 
La ley de subcontratación y la tutela de los derechos fundamentales de los trabajadores de servicios transitorios

conflicto si bien tiene su origen o incluso su conformación en el seno de la empresa, trasciende este espacio para ubicarse en sede constitucional. No obstante, cualquier interpretación sobre los eventuales límites a un derecho fundamental ha de llevarse a cabo restrictivamente dada la fuerza expansiva que poseen éstos y que exigen una opción inequívoca por su aplicación plena. Del mismo modo que los derechos fundamentales no son absolutos, los límites que se impongan a su ejercicio, derivados del reconocimiento de otros bienes jurídicos constitucionales, tampoco pueden serlo. Es por eso, entonces, que los alcances particulares que respecto de la EU pueda tener la incidencia de los derechos fundamentales de los trabajadores transitorios es una materia que tendrá que ser particularizada por la jurisprudencia judicial al momento de tener que pronunciarse sobre eventuales lesiones a estos derechos.

Por otra parte, conforme al dictamen corresponde tener en consideración, a juicio de la Dirección del Trabajo, que en la relación laboral el derecho fundamental del trabajador se inserta, en cuanto a su ejercicio, en el específico ámbito de la organización empresarial, en la que se produce evidentemente una compresión o modulación de su personalidad, lo que responde a la estructura jerárquica de esta organización y va a repercutir en el alcance que éstos puedan llegar a tener respecto del ejercicio de los poderes de dirección y control del empleador y, en concreto, respecto de la especiales potestades que se le reconocen a la EU sin ser contraparte de la relación laboral. Esto último cobra también una especial significación respecto de las medidas de control que pueda aplicar la EU, las que deberán matizarse de tal manera de armonizar los legítimos fines empresariales con las garantías de generalidad, impersonalidad, idoneidad del control y respeto de la dignidad del trabajador transitorio, tal como lo exige de manera categórica el artículo 154 inciso final del $\mathrm{CdT}^{81}$ Por tanto, las modulaciones al ejercicio de los derechos fundamentales que la relación laboral impone tienen que ser las indispensables y estrictamente necesarias para satisfacer un interés empresarial merecedor de tutela y protección, de manera que si existen otras posibilidades de satisfacer dicho interés menos agresivas y afectantes del derecho en cuestión, habrá que emplear estas últimas, en base a los principios de proporcionalidad e intervención mínima. ${ }^{82}$

Lo recientemente señalado cobra natural incidencia práctica respecto del suministro de trabajadores y va a dar lugar a una especial dimensión a esta relación entre dos sujetos que no están unidos por ningún vínculo contractual, por lo que se refuerza el ámbito de vigencia efectiva

José Luis, "Los derechos fundamentales del empleador: el nuevo procedimiento de tutela laboral”, ob. cit., p. $18 \mathrm{~s}$.

81 Sobre la incidencia de los derechos fundamentales del trabajador frente a las medidas de control por parte del empleador véase: Caamaño Rojo, Eduardo, "La eficacia de los derechos fundamentales en las relaciones laborales y su reconocimiento por la Dirección del Trabajo”, ob. cit., p. 37 s. Véase también el dictamen de la Dirección del Trabajo N ${ }^{\circ} 8273 / 337$ de fecha 19 de diciembre de 1995 en el cual se consolidan los criterios para validar la implementación de medidas de control. 
de los derechos fundamentales entre ciudadanos, amparando especialmente al trabajador transitorio de los eventuales excesos que podrían derivarse del ejercicio del poder de dirección y control de los servicios por parte del empleador. Por tal motivo, la más importante función a asignar a los derechos fundamentales en la empresa es que ellos se erigen como el principal límite a los poderes empresariales. En efecto, el régimen de libertades y derechos consagrados y reconocidos constitucionalmente lleva necesariamente asociado un sistema de límites a los poderes empresariales, debiendo darse primacía a aquellos por sobre éstos. ${ }^{83}$ Esta función limitadora de los derechos fundamentales se desarrollará en el conjunto y en la totalidad de la relación de trabajo al interior de la EU, pues allí donde se ejerzan los poderes empresariales siempre estará presente esta perspectiva limitadora de los derechos fundamentales. ${ }^{84}$

Finalmente resulta interesante resaltar que la ley de subcontratación haya considerado la aplicación a favor de los trabajadores transitorios, en el artículo 183-Y inciso 2 del CdT, de la misma norma del artículo 154 bis con el fin de mantener la reserva y confidencialidad de toda la documentación privada de los trabajadores de la que pueda tomar conocimiento la EU con ocasión del suministro de trabajadores. ${ }^{85}$ De este modo se refuerza la idea que la intimidad y vida privada de los trabajadores constituye un límite al ejercicio de las facultades de administración del empleador, en términos que se le prohíbe al empleador divulgar la información y datos privados del trabajador a que tenga acceso con ocasión de la relación laboral, ${ }^{86}$ lo que debe entenderse en directa relación con las disposiciones de la Ley $\mathrm{N}^{\circ} 19.628$ sobre protección de la vida privada. ${ }^{87}$

\subsection{Los derechos olvidados}

Sin perjuicio de lo señalado en los párrafos anteriores, no es posible obviar que la Ley $\mathrm{N}^{\mathrm{o}}$ 20.123 dista de ser verdaderamente consecuente en el reconocimiento de los derechos fundamentales que detenta el trabajador transitorio en su condición de persona y trabajador, ya que ha dejado de lado o al menos olvidado, dos garantías constitucionales que resultan imprescindibles para asegurar un desarrollo de la subcontratación de servicios personales en

En esta misma línea de pensamiento, López, Diego, "Los derechos fundamentales en el trabajo”, ob. cit., p. 2. Melis, Christian, "Derechos fundamentales y empresas: apuntes para una configuración dogmático-jurídica", ob. cit., p. 105-106. En igual sentido: Fernández, Luis, Las facultades empresariales de control de la actividad laboral, ob. cit., p. 33 s.

85 En relación con esta materia, el artículo 6 del Convenio $\mathrm{N}^{\mathrm{o}} 181$ de la OIT sobre las agencias de empleo privadas establece que: "El tratamiento de los datos personales de los trabajadores por las agencias de empleo privadas deberá: a) efectuarse en condiciones que protejan dichos datos y que respeten la vida privada de los trabajadores, de conformidad con la legislación y la práctica nacionales; b) imitarse a las cuestiones relativas a las calificaciones y experiencia profesional de los trabajadores en cuestión y a cualquier otra información directamente pertinente." Mejía, Sergio; Lizama, Luis, Reformas laborales. Su contenido e impacto en la empresa, Editorial Jurídica Cono Sur, Santiago, Chile, 2001, p. 167-168.

Publicada en el Diario Oficial de fecha 28 de agosto de 1998. 
La ley de subcontratación y la tutela de los derechos fundamentales de los trabajadores de servicios transitorios

condiciones de equidad, plena protección social y erradicación definitiva de los riesgos de precarización de esta forma de empleo. En concreto, nos referimos al reconocimiento del derecho de igualdad de trato del trabajador transitorio respecto del trabajador permanente de la EU y a libertad sindical, materializada en posibilidad cierta de ejercer una actuación colectiva en busca de mejores condiciones laborales a través de la sindicación y el derecho a negociar colectivamente.

En lo que respecta a la igualdad de trato, ${ }^{88}$ es claro que el legislador nacional producto de las arduas discusiones políticas que precedieron a la ley de subcontratación y, tal vez, con el fin de no encarecer esta forma de empleo, ante la presión de los grupos de pensamiento de corte más neoliberal, no incluyó una norma que suele ser de rigor en el Derecho Comparado ${ }^{89}$ respecto del suministro de trabajadores y que tiene por objeto asegurar un trato laboral igualitario entre trabajadores permanentes y transitorios, particularmente en el plano salarial, evitando que estos últimos tengan una categoría inferior o de segunda clase al interior de la EU. Este problema es de enorme relevancia si se atiende a las ya graves diferencias o, derechamente, discriminaciones que se presentan en Chile en especial respecto de ciertos grupos de trabajadores como es el caso de los jóvenes y las mujeres, quienes podrían ser los colectivos para quienes pudiera llegar a resultar más interesante, conveniente o plausible esta forma de contratación en un cierto momento de su trayectoria laboral. Es por eso que resulta de verdad lamentable, como lo sostiene con acierto Ugarte, ${ }^{90}$ que en rigor, las propuestas del Gobierno no hayan buscado

88 Sobre la materia: Caamaño Rojo, Eduardo, "El principio de igualdad de trato en el Derecho del Trabajo", Revista de Derecho, Pontificia Universidad Católica de Valparaíso, Vol. XXI - 2000, p. 27 s.

89 Este es el caso, por ejemplo, del artículo 11 de la Ley española No $14 / 1994$ que establece normas reguladoras de las empresas de trabajo temporal, modificado por la Ley $\mathrm{N}^{\circ}$ 29/1999, conforme al cual: "Los trabajadores contratados para ser cedidos a empresas usuarias tendrán derecho durante los períodos de prestación de servicios en las mismas a percibir, como mínimo, la retribución total establecida para el puesto de trabajo a desarrollar en el convenio colectivo aplicable a la empresa usuaria, calculada por unidad de tiempo. Dicha remuneración deberá incluir, en su caso, la parte proporcional correspondiente al descanso semanal, las pagas extraordinarias, los festivos y las vacaciones, siendo responsabilidad de la empresa usuaria la cuantificación de las percepciones finales del trabajador. A tal efecto, la empresa usuaria deberá consignar dicho salario en el contrato de puesta a disposición del trabajador.” Del mismo modo, la Propuesta modificada de Directiva del Parlamento Europeo, de 28 de noviembre de 2002, relativa a las condiciones de trabajo de los trabajadores cedidos por empresas de trabajo temporal, contiene entre sus normas centrales la consagración del principio de no discriminación para los trabajadores cedidos por las empresas de trabajo temporal, señalando que sus condiciones fundamentales de trabajo y empleo, incluidos el tiempo de trabajo y la remuneración, serán por lo menos las que les serían aplicables si los contratara directamente la empresa usuaria. Por su parte, el artículo 5 del Convenio 181 de la OIT de 1997 sobre las agencias de empleo privadas establece que: "Con el fin de promover la igualdad de oportunidades y de trato en materia de acceso al empleo y a las diferentes profesiones, todo Miembro velará por que las agencias de empleo privadas traten a los trabajadores sin discriminación alguna por razones de raza, color, sexo, religión, opinión política, ascendencia nacional, origen social o cualquier otra forma de discriminación cubierta en la legislación y la práctica nacionales, tales como la edad o la discapacidad."

$90 \quad$ Ugarte Cataldo, José Luis, "Sobre relaciones laborales triangulares: la subcontratación y el suministro de trabajadores," ob. cit., p. 27-28. 
solucionar directamente este problema de las diferencias remuneracionales entre estos tipos de trabajadores, ya que en la ley de subcontratación, ni en su versión original, ni en las últimas indicaciones al proyecto aprobado, se recoge ni da respuesta a este problema, por lo que sigue siendo plenamente legal establecer condiciones de remuneraciones inferiores para los trabajos suministrados, a pesar de realizar el mismo trabajo que los dependientes permanentes de la EU. Esto último resulta impresentable desde el punto de vista del debido respeto de los derechos fundamentales en el ámbito de la empresa y de las condiciones laborales mínimas que el Estado debe garantizar para que pueda existir un trabajo decente.

Existe por eso en este plano un punto débil en la Ley No 20.123 que debería subsanarse en una revisión de su contenido en un breve o mediano plazo, particularmente, si se tiene en cuenta que el derecho a la igualdad de trato y a la no discriminación laboral se encuentran matizados respecto de los trabajadores transitorios, ya que al no tener una relación contractual con la EU no están en condiciones de reclamar un trato similar a los trabajadores permanentes de esa empresa por la realización de trabajo de igual o similar valor. No avanzar en este sentido implicará, por lo demás, perpetuar las condiciones de precariedad de los trabajadores transitorios que la ley de subcontratación procuró revertir, agravar la inequidad salarial ya existente en Chile y profundizar el estigma de ser trabajadores de segunda categoría, lo que repugna con el respeto mínimo que se debe a todo trabajo humano fundado en la dignidad de la persona que lo realiza.

Finalmente, procede llamar la atención sobre los otros derechos fundamentales de los trabajadores transitorios que fueron olvidados por la Ley $\mathrm{N}^{\circ} 20.123$ y que son los de sindicación y de negociación colectiva, los que al no recibir un tratamiento especial acorde con las particularidades de la relación jurídica triangular que da forma al suministro de trabajadores quedarán sujetos a las reglas generales del CdT, todo lo cual redundará en su más absoluta ineficacia. Esto se explica, porque las posibilidades reales de poder constituir un sindicato de empresa en la EST se verán limitadas al operar éstas, por regla general, sin una plantilla permanente de trabajadores transitorios, ya que los contratarán únicamente a requerimiento de las EU, al momento de negociar y celebrar un contrato de puesta a disposición, por lo que las EST operarán más bien con bases de datos de trabajadores, siendo éstos llamados a prestar servicios cuando sean verdaderamente requeridos. Por esta misma razón las posibilidades de una negociación colectiva de los trabajadores transitorios con su empleadora son meramente nominales, sobre todo, si se tiene en cuenta que sus condiciones de trabajo no están determinadas directamente por su empleador, sino que por las EU donde prestan servicios, las que tienen sus propios sindicatos y regulaciones colectivas, de los que quedarán marginados los trabajadores cedidos por la EST. $^{91}$

En este sentido: Ugarte Cataldo, José Luis, "Sobre relaciones laborales triangulares: la subcontratación y el suministro de trabajadores", ob. cit., p. 29. 
La ley de subcontratación y la tutela de los derechos fundamentales

de los trabajadores de servicios transitorios

En definitiva, sin una solución específica para esta nueva realidad laboral que remueve los cimientos tradicionales a partir de los cuales se construye la relación laboral normal y el reconocimiento de los derechos colectivos, las garantías fundamentales asociadas a la libertad sindical que Chile ha priorizado luego de la ratificación de los Convenios $N^{\circ} 87$ y 98 de la OIT amenazan por convertirse en privilegios o en normas de contenido vacío, lo que resulta muy grave en aras de promover un desarrollo económico asociado verdaderamente a la justicia social. Por ello, entonces, urge determinar nuevas formas de asociatividad sindical en el ámbito interempresa y de negociación que incluyan también a los trabajadores que comienzan a ser marginados de la tutela específica del Derecho Colectivo del Trabajo por causa del crecimiento explosivo de formas atípicas de empleo. Así lo reconoce expresamente el Convenio $\mathrm{N}^{\mathrm{o}} 181 \mathrm{de}$ la OIT, aún no ratificado por Chile, sobre las agencias de empleo privadas al disponer en su artículo 4 que: "Se adoptarán medidas para asegurar que los trabajadores contratados por las agencias de empleo privadas que prestan los servicios a los que se hace referencia en el artículo 1 no se vean privados del derecho de libertad sindical y del derecho a la negociación colectiva."

Sin perjuicio de lo anterior, nuestro país se encuentra vinculado por la Declaración de Principios y Derechos Fundamentales de la OIT, la que en su punto 2 señala que: “...todos los Miembros, aun cuando no hayan ratificado los convenios aludidos, tienen un compromiso que se deriva de su mera pertenencia a la Organización de respetar, promover y hacer realidad, de buena fe y de conformidad con la Constitución, los principios relativos a los derechos fundamentales que son objeto de esos convenios, es decir: a) la libertad de asociación y la libertad sindical y el reconocimiento efectivo del derecho de negociación colectiva...".

\section{Las posibilidades reales de tutela jurisdiccional de los derechos fundamentales del trabajador transitorio}

Como hemos tenido oportunidad de establecerlo, es indudable que el efecto irradiador de los derechos fundamentales que se le reconocen al trabajador transitorio en su calidad de persona y ciudadano tienen eficacia respecto de su particular situación frente a la EU y posibilitarán, idealmente, un mejoramiento de su condición laboral, estableciendo límites y garantías respecto de aquellas materias que digan relación concreta con su prestación de servicios y vida al interior de esa empresa, más allá de las normas especiales que sobre este tipo de subcontratación estableció la Ley $\mathrm{N}^{\mathrm{o}}$ 20.123. Con todo, un adecuado reconocimiento de los derechos fundamentales a la interior de la empresa no se agota con estas consideraciones ni menos con la aceptación de su eficacia en el derecho sustantivo. Esto es así, porque lo determinante serán las posibilidades ciertas de tutela jurisdiccional que puedan alcanzar en el evento de sufrir una lesión o vulneración y que le aseguren al trabajador transitorio su respeto ante la EU, haciendo realidad su contenido de libertad y de respeto a la dignidad de la persona implícitos en el contenido particular de cada uno de estos derechos fundamentales, pues las libertades civiles no tienen contenido si carecen de posibilidad de recurrir a los órganos del Estado, ya sean éstos 
autoridades judiciales o administrativas. ${ }^{92}$

Por tal motivo, entonces, es necesario establecer si el procedimiento de tutela incorporado al CdT por la Ley $\mathrm{N}^{\circ} 20.087$, cuya entrada en vigencia se espera para marzo de 2008 , y que idealmente vendrá a poner fin a la actual insuficiencia del ordenamiento jurídico para proteger los derechos fundamentales en el ámbito de la empresa será aplicable respecto del trabajo transitorio, cumpliendo así el objetivo esbozado en el párrafo anterior. Para estos efectos, nos ocuparemos de resolver algunas interrogantes en relación con la situación particular de los trabajadores transitorios sin entrar al análisis pormenorizado del desarrollo de este procedimiento, por exceder ello de los límites de estudios. ${ }^{93}$

Atendido lo anterior, corresponde primeramente efectuar una referencia al nuevo artículo 485 del CdT en el cual se precisa el objeto de este procedimiento, señalando su inciso 1 que: "El procedimiento contenido en este Párrafo se aplicará respecto de las cuestiones suscitadas en la relación laboral por aplicación de las normas laborales, que afecten derechos fundamentales de los trabajadores...". Luego, esta disposición procede a una cuestionable enunciación de los derechos fundamentes susceptibles de ser tutelados por este procedimiento lo que ha implicado una limitación artificial de su ámbito de aplicación con respecto al proyecto de ley y que da cuenta de una lamentable tergiversación de su sentido originario por parte del Congreso Nacional a causa de las presiones políticas que lo rechazaban. En efecto, producto de esta enunciación cerrada de garantías constitucionales susceptibles de ser protegidas en su ejercicio en el ámbito de la empresa a través de este procedimiento, se desprende que existirán en Chile derechos fundamentales de primera y segunda clase, siendo estos últimos aquellos derechos excluidos del artículo 485 del CdT, como es el caso, por ejemplo, del derecho a la educación, el que podría verse conculcado si el empleador limita en los hechos las posibilidades del trabajador de educarse, o bien, del derecho a vivir en un medio ambiente libre de contaminación.

A continuación, cabe destacar que el artículo 485 inciso 3 del CdT dispone que: "Se entenderá que los derechos y garantías a que se refieren los incisos anteriores resultan lesionados

Supiot, Alain, Crítica del Derecho del Trabajo, ob. cit., 187. Además, como lo plantea Ugarte, no se puede desconocer que en Chile ha predominado una concepción tradicional de la tutela judicial, propia de los orígenes del Derecho del Trabajo, que entiende como único litigio laboral digno de amparo jurisdiccional el que involucra derechos directamente avaluables en términos económicos, y sobre la cual se ha construido la mayor parte de la estructura procedimental del CdT. Por tanto no ha habido en ese escenario ni tiempo ni ganas para la creación de espacios procesales que tengan por objeto el amparo de derechos no patrimoniales, vinculados más que al intercambio de trabajo por salario, a la dimensión moral del sujeto entendido como ciudadano. En este sentido: Ugarte Cataldo, José Luis, El nuevo Derecho del Trabajo, ob. cit., p. 130-131.

93 Véase: Ugarte Cataldo, José Luis, "Los derechos fundamentales del empleador: el nuevo procedimiento de tutela laboral", ob. cit., p. 10 s.; Caamaño Rojo, Eduardo, El derecho a la no discriminación en el empleo, ob. cit., p. 173 s.; Gamonal Contreras, Sergio, El procedimiento de tutela de los derechos laborales, Editorial Lexis Nexis, Santiago, Chile, 2007. 
La ley de subcontratación y la tutela de los derechos fundamentales de los trabajadores de servicios transitorios

cuando el ejercicio de las facultades que la ley le reconoce al trabajador limita el pleno ejercicio de aquellas sin justificación suficiente, en forma arbitraria o desproporcionada, o sin respeto de su contenido esencial. En igual sentido se entenderán las represalias ejercidas en contra de trabajadores, en razón o como consecuencia de la labor fiscalizadora de la Dirección del Trabajo o por el ejercicio de acciones judiciales." De la norma transcrita es posible inferir dos conclusiones de gran relevancia jurídica:

a) El artículo 485 inciso 3 del CdT tipifica un ilícito laboral objetivo, al igual que lo hace el artículo 2 inciso 3 de este cuerpo legal al conceptualizar los actos de discriminación, por lo que para su consumación no se debe atender a aspectos volitivos del comportamiento del empleador, en concreto, a la culpa o dolo implícita en el desarrollo de conducta. Por tanto, este ilícito se configura cuando el empleador limita el ejercicio de los derechos fundamentales del trabajador en forma desproporcionada o arbitraria, o bien, cuando atenta contra la garantía de indemnidad - elevada prácticamente por esta disposición a la categoría de un derecho esencial del trabajador ${ }^{94}$ - ejerciendo represalias en contra de trabajadores que han hecho valer sus derechos ante el organismo fiscalizador del trabajo o ante los Tribunales de Justicia.

b) El artículo 485 inciso 3 del CdT al definir que se entiende por lesión de derechos fundamentales parte del supuesto que el único sujeto posiblemente agresor de los derechos fundamentales del trabajador $y$, por tanto, el sujeto pasivo en el procedimiento de tutela será el empleador. ${ }^{95}$ Lo anterior se puede explicar, porque el artículo 485 inciso 3 del CdT es el correlato inmediato del artículo 5 inciso 1 de este cuerpo legal, por lo tanto, cuando el empleador no limita justificadamente el ejercicio de sus potestades de dirección y control en base al respeto de los derechos fundamentales del trabajador, incurre en el ilícito laboral recién referido, habilitando al trabajador, a condición de que la garantía conculcada esté dentro de aquellas expresa y taxativamente previstas por el artículo 485 inciso 1 del CdT, a ejercer la acción de tutela en su contra.

Ahora bien, esta segunda conclusión no es indiferente para el tema que nos ocupa, pues podrían generarse dudas acerca de la procedencia efectiva del procedimiento de tutela en el caso de que se lesionen derechos fundamentales del trabajador transitorio por parte de la EU. En efecto, si se asumiera una interpretación literal del artículo 485 inciso 3 del CdT habría que entender el término "empleador" en base al concepto contenido en el artículo 3 letra a) del mismo texto legal, vale decir, "la persona natural o jurídica que utiliza los servicios intelectuales

94 En este sentido: Ugarte Cataldo, José Luis, "Los derechos fundamentales del empleador: el nuevo procedimiento de tutela laboral", ob. cit., p. 17.

95 Igual opinión sostiene Ugarte Cataldo, José Luis, "Los derechos fundamentales del empleador: el nuevo procedimiento de tutela laboral”, ob. cit., p. 14-15. 
o materiales de una o más personas en virtud de un contrato de trabajo." Por tanto, en la subcontratación de servicios personales el empleador es la EST y no la EU, de acuerdo a la definición del contrato de trabajo de servicios transitorios contenido en el nuevo artículo 183$\mathrm{R}$ del CdT. Esta interpretación basada únicamente en el tenor literal de las normas citadas podría resultar tremendamente peligrosa, ya que haría ilusoria la tutela jurisdiccional de los derechos fundamentales de los trabajadores transitorios frente a la conculcación de estos por la EU, lo que transformaría a la disposición del artículo 183-Y del CdT en una norma meramente declarativa.

Por lo anterior, creemos que debe efectuarse una interpretación finalista de las disposiciones de los artículos 183-Y y 485 del CdT, en el sentido de aceptar plenamente que los trabajadores transitorios puedan hacer valer el amparo particular de este procedimiento especial de derechos fundamentales frente a la EU, en base a las características propias de la relación laboral atípica a que da lugar el suministro de trabajadores. En efecto, es la EU quien, a pesar de no ser formalmente parte empleadora en esta relación jurídica laboral de carácter triangular, detentará en la práctica los poderes de dirección y control sobre los servicios que preste el trabajador transitorio, según se señala de manera explícita por los artículos $183-\mathrm{X}$ y $183-\mathrm{W}$ del CdT, y serán precisamente estas potestades de las que carece la EST, las que podrían lesionar los derechos fundamentales del trabajador en caso de ejercerse de manera arbitraria o desproporcionada. Es por ello, entonces, que se puede entender que el artículo 183-Y del CdT es la proyección directa, para el ámbito del suministro de trabajadores, de la disposición general del artículo 5 inciso 1, y debe por cierto cobrar una verdadera y real eficacia, lo que tendrá lugar exclusivamente si se le reconoce la potencialidad de contar con un mecanismo de tutela jurisdiccional a través del nuevo procedimiento regulado a partir del artículo 485 del CdT.

A su vez, no se puede olvidar que ese es el sentido original perseguido mediante la reforma procesal laboral contenida en la Ley $\mathrm{N}^{\circ} 20.087$, pues como se señala en el Mensaje con el cual se inició su tramitación legislativa, la razón de incorporar el procedimiento de tutela obedece a “...la necesidad de potenciar la vigencia plena, en el ámbito jurídico laboral, de los derechos que el trabajador detenta no sólo en cuanto trabajador, sino que también en su condición de persona (...) Se trata, en definitiva, del posicionamiento de los derechos fundamentales como ejes vertebradores de unas relaciones laborales plenamente democráticas." 96

Por todo lo dicho, entonces, creemos que el reconocimiento efectivo de los derechos fundamentales de los trabajadores transitorios ante la EU no se limita a únicamente al plano del Derecho sustantivo, sino que alcanza real dimensión y toda su potencialidad de incorporar un haz adicional de protección a la persona del trabajador, mediante la alternativa cierta y consistente de habilitarlos, en caso de ser vulneradas sus garantías esenciales, para recurrir a los Tribunales 
La ley de subcontratación y la tutela de los derechos fundamentales

de los trabajadores de servicios transitorios

de Justicia reclamando el amparo jurisdiccional de estos derechos, incluidos los eventuales resarcimientos, en contra de las EU que pudieran lesionarlos en el ejercicio las potestades que le reconoce la ley de subcontratación.

\section{Palabras finales}

La tan esperada ley de subcontratación ha repercutido directamente en la forma de entender la regulación y protección del trabajo subordinado, abriendo las puertas para la incorporación de modalidades atípicas de contratación laboral que resultaban inimaginables hace algunas décadas. Este es el caso particular de la subcontratación de servicios personales y su repercusión en el concepto y rol tradicional del empleador, como asimismo, en la alteración de la bilateralidad que caracteriza y define una relación jurídica basada en el contrato individual de trabajo.

En este nuevo escenario, resultante de un profundo proceso de transformación de la organización empresarial y de la ordenación del trabajo subordinado con miras a poder hacer frente al nuevo panorama económico globalizado, los derechos fundamentales del trabajador en su condición de persona vienen a constituir una salvaguarda necesaria de su libertad y dignidad ante la insuficiencia de un sistema normativo que es incapaz muchas veces de dar respuestas eficaces y oportunas, en un contexto, además, caracterizado por la falta de pleno convencimiento acerca de las potencialidades del Derecho del Trabajo para hacer frente al nuevo orden económico y a las aspiraciones de desarrollo. Desde este punto de vista Chile no ha estado al margen de la renovada visión dogmática jurídica que posiciona el tema de la ciudadanía en la empresa como una forma de ampliar y profundizar la protección del trabajador, como a su vez, de ver, entender y aplicar los principios e instituciones que son propios del Derecho del Trabajo. En esta línea se inscriben las reformas introducidas por la Ley N ${ }^{\circ} 19.759$ particularmente en los artículos 2, 5 inciso $1^{\circ}$ y 154 inciso final del CdT. Por su parte, la ley de subcontratación hace suya también esta manera distinta de proteger al trabajador e incorpora una norma expresa que potencia y refuerza, al menos en el plano del derecho sustantivo, el respeto que se debe a los derechos fundamentales del trabajador en cuanto persona al interior de la empresa.

Con todo, a pesar de los avances normativos en este plano y que fueron objeto de análisis en este estudio, se mantiene la deficiencia del sistema de tutela jurisdiccional de los derechos fundamentales para garantizar efectivamente su vigencia al interior de la empresa. Por eso fue una mala señal la postergación de la entrada en vigencia de la tan anhelada reforma procesal laboral, ya que junto con dar cuenta de una falta de diligencia del Gobierno en su implementación se sigue haciendo ilusoria la protección eficaz de los derechos fundamentales en el plano jurisdiccional, sin la cual estas garantías se transforman en meras palabras vacías, contribuyendo a debilitar las bases a partir de las cuales se debería asentar sólidamente nuestro estado de derecho. Además, la circunstancia que se haya dejado fuera de la ley de subcontratación el derecho a la igualdad de trato entre el trabajador transitorio y el trabajador permanente de la 
empresa usuaria o no se avance significativamente en la promoción y defensa de los derechos colectivos de los trabajadores sigue demostrando que estamos aún a medio camino de tener un sistema jurídico de protección del trabajo que sea acorde con los valores de justicia social y de solidaridad.

A pesar de ello, privilegiando una visión más optimista, hay que apreciar que la incorporación de la temática de la ciudadanía en la empresa respecto de la subcontratación de servicios personales contribuirá a darle una nueva dimensión a esta normativa y podría contribuir a generar un cambio en el rol que cumplan en el futuro la EST y las EU, en vistas a armonizar sus intereses y necesidades particulares con un adecuado respeto de los derechos de los trabajadores y así aprovechar las ventajas que puede ofrecer la subcontratación laboral. Por lo anterior es de esperar que jueces y abogados, así como los sindicatos y la Dirección del Trabajo que cumplirán un rol protagónico en el futuro como sujetos del nuevo proceso de tutela velen por no desvirtuar su sentido propio y contribuyan a materializar el respeto pleno de los derechos fundamentales para todos los trabajadores, en concordancia con los legítimos intereses y derechos de los empleadores.

\section{Bibliografía}

- Caamaño Rojo, Eduardo, El principio de igualdad de trato en el Derecho del Trabajo, en Revista de Derecho, Pontificia Universidad Católica de Valparaíso, Vol. XXI - 2000.

- Caamaño Rojo, Eduardo, El derecho a la no discriminación en el empleo, Editorial Lexis Nexis, Santiago, Chile, 2005.

- Caamaño Rojo, Eduardo, Las transformaciones del trabajo, la crisis de la relación laboral normal y el desarrollo del empleo atípico, en Revista de Derecho de la Facultad de Ciencias Jurídicas y Sociales, Universidad Austral de Chile - Valdivia, volumen XVIII, julio 2005.

- Caamaño Rojo, Eduardo, La eficacia de los derechos fundamentales en las relaciones laborales y su reconocimiento por la Dirección del Trabajo, en Revista de Derecho, Pontificia Universidad Católica de Valparaíso, Vol. XXVII, Semestre I, 2006.

- Caamaño Rojo, Eduardo, La tutela jurisdiccional de la libertad sindical, Revista de Derecho de la Facultad de Ciencias Jurídicas y Sociales, Universidad Austral de Chile - Valdivia, volumen XIX, julio 2006.

- Cruz Villalón, Jesús, Outsourcing y relaciones laborales, en VV.AA., Descentralización productiva y nuevas formas organizativas del Trabajo, Colección Informes y Estudios, Ministerio del Trabajo y Asuntos Sociales, Madrid, España, 2000.

- Del Rey Guanter, Salvador; Gala Durán, Carolina, Trabajo autónomo y descentralización productiva: nuevas perspectivas de una relación en progresivo desarrollo y dependencia, documento disponible en www.ceveal.com/autonomos.htm.

- Dieterich, Thomas; Hanau, Meter; Schaub, Günter, Erfurter Komentar zum Arbeitsrecht,

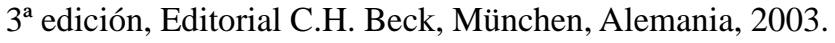

- $\quad$ Echeverría, Magdalena; Solís, Valeria; Uribe, Verónica, El otro trabajo: el suministro de 
La ley de subcontratación y la tutela de los derechos fundamentales de los trabajadores de servicios transitorios

trabajadores en las empresas, Cuaderno de Investigación $N^{\circ}$ 7, Dirección del Trabajo, Santiago, Chile, 1998.

- Echeverría Tortello, Magdalena, Los riesgos laborales de la subcontratación, Aporte al Debate Laboral No 9, Departamento de Estudios de la Dirección del Trabajo, abril 2006, disponible en www.dt.gob.cl.

- Fernández Villazón, Luis, Las facultades empresariales de control de la actividad laboral, Editorial Aranzadi, Navarra, España, 2003.

- Gamonal Contreras, Sergio, La ciudadanía en la empresa o los derechos fundamentales inespecíficos, Editorial Fundación de Cultura Universitaria, Montevideo, Uruguay, 2004.

- García Murcia, Joaquín, Contratas y subcontratas, Revista del Ministerio del Trabajo y Asuntos Sociales No 48, España, 2004.

- Koch, Carlos, Contratos de provisión de trabajadores. La relación laboral de trabajo triangular, Revista Laboral Chilena, febrero marzo 1997.

- Lanata Fuenzalida, Gabriela, Contrato individual de trabajo, Editorial Lexis Nexis, Santiago, Chile, 2006.

- $\quad$ Lizama Portal, Luis; Ugarte Cataldo, José Luis, Interpretación y derechos fundamentales, Editorial Jurídica Cono Sur, Santiago, Chile, 1998.

- $\quad$ Lizama Portal, Luis, Derecho del Trabajo, Editorial Lexis Nexis, Santiago, Chile, 2003.

- $\quad$ López, Diego, Los derechos fundamentales en el trabajo: garantía de libertad y dignidad de las personas que trabajan, en Temas Laborales de la Dirección del Trabajo 22, noviembre 2004.

- Mejía, Sergio; Lizama, Luis, Reformas laborales. Su contenido e impacto en la empresa, Editorial Jurídica Cono Sur, Santiago, Chile, 2001.

- Melis, Christian, Derechos fundamentales y empresas: apuntes para una configuración dogmático-jurídica, Anuario de Derecho del Trabajo y Seguridad Social Nr. 3/2004, Derechos Fundamentales. Homenaje al Profesor Patricio Novoa Fuenzalida, Sociedad Chilena de Derecho del Trabajo y de la Seguridad Social.

- Monereo, José Luis, La responsabilidad empresarial en los procesos de subcontratación: puntos críticos, ediciones Ibidem, Madrid, España, 1994.

- Monereo Pérez, José Luis; Moreno Vida, María Nieves, Las empresas de trabajo temporal en el marco de las nuevas formas de organización empresarial, Revista del Ministerio del Trabajo y Asuntos Sociales No 48, España, 2004.

- Palavecino, Claudio, Subcontratación. Régimen jurídico del trabajo subcontratado y del suministro de personal, Editorial Jurídica de Chile, Santiago, Chile, 2006.

- $\quad$ Rivero Lamas, Juan, La descentralización productiva y las nuevas formas organizativas del trabajo, en VV.AA., Descentralización productiva y nuevas formas organizativas del Trabajo, Colección Informes y Estudios, Ministerio del Trabajo y Asuntos Sociales, Madrid, España, 2000.

- $\quad$ Rojas Miño, Irene, Los desafíos actuales del Derecho del Trabajo en Chile, Revista Ius et Praxis, Facultad de Ciencias Jurídicas y Sociales, Universidad de Talca, Año 12, $\mathrm{N}^{\mathrm{o}} 1$, 2006. 
- Sáez, Felipe, El reconocimiento de los derechos fundamentales al interior de la empresa en las reformas laborales, Boletín Oficial de la Dirección del Trabajo, noviembre 2001.

- $\quad$ Supiot, Alain, Crítica del Derecho del Trabajo, Colección Informes y Estudios $N^{\circ} 11$, Ministerio del Trabajo y Asuntos Sociales, Madrid, 1996.

- Torres Díaz, Roberto, La reforma laboral, los contratistas y las empresas de servicios transitorios, Revista Laboral Chilena, julio 2001 (Parte I).

- $\quad$ Ugarte Cataldo, José Luis, Suministro de trabajadores y trabajo temporal. ¿Empresas sin trabajadores?, Revista Laboral Chilena, junio 1998.

- Ugarte Cataldo, José Luis, La descentralización productiva: la nueva moda en las relaciones laborales, Revista Laboral Chilena, enero 2001.

- $\quad$ Ugarte, José Luis, Los derechos fundamentales y las relaciones laborales: en el mundo de las palabras, Anuario de Derecho del Trabajo y Seguridad Social Nr. 3/2004, Derechos Fundamentales. Homenaje al Profesor Patricio Novoa Fuenzalida, Sociedad Chilena de Derecho del Trabajo y de la Seguridad Social.

- $\quad$ Ugarte Cataldo, José Luis, El nuevo Derecho del Trabajo, Editorial Universitaria, Santiago, Chile, 2004.

- Ugarte Cataldo, José Luis, Sobre las relaciones triangulares: la subcontratación y el suministro de trabajadores, Revista Ius et Praxis, Facultad de Ciencias Jurídicas y Sociales, Universidad de Talca, Año 12, No 1, 2006.

- Ugarte Cataldo, José Luis, Los derechos fundamentales del empleador: el nuevo procedimiento de tutela laboral, Colección Ensayos Jurídicos № 2, Facultad de Derecho, Universidad Alberto Hurtado, 2006.

- Walker Errázuriz, Francisco, Derecho de las Relaciones Laborales, Editorial Universitaria, Santiago, Chile, 2003. 